\title{
Los caminos del olvido y los rituales políticos durante el gobierno de la conciliación nacional en \\ Costa Rica (1958-1962)
}

\author{
The Paths of Oblivion and Political Rituals \\ during the Government of National Conciliation \\ in Costa Rica (1958-1962)
}

\section{Os caminhos do esquecimento e os rituais políticos durante o governo da conciliação nacional na Costa Rica (1958-1962)}

\begin{abstract}
Alexia Ugalde Quesada*
Resumen: Este artículo plantea que durante el gobierno de Mario Echandi Jiménez (1958-1962) se dio un proceso de conciliación nacional, analizado mediante la implementación de lo que hemos llamado «medidas de compensación» y «rituales políticos de inclusión», los cuales favorecieron a los perdedores de la guerra civil de 1948. Por ejemplo, el regreso de Rafael Ángel Calderón Guardia a Costa Rica y la declaración de una segunda amnistía para todas las personas vinculadas con el conflicto bélico. Por último, se concluye que el proceso de conciliación nacional también se vio favorecido por la intensificación del movimiento opositor a la dictadura somocista, pues esto generó una nueva configuración del «enemigo» caracterizándolo como extranjero, a su vez, esto promovió la unidad interna.
\end{abstract}

Fecha de recepción: 08/09/2020 - Fecha de aceptación: 30/12/2020

* Costarricense. Máster en Historia por la Universidad de Costa Rica (UCR), San José, Costa Rica. Docente en la Sede de Occidente, Universidad de Costa Rica (UCR), Alajuela, Costa Rica. Docente en la Maestría en Psicología Comunitaria e investigadora del Centro de Investigaciones Históricas de América Central (CIHAC), Universidad de Costa Rica (UCR), San José, Costa Rica. Correo electrónico: alexia.ugalde@ucr.ac.cr. ORCID: https://orcid.org/0000-0001-5235-8846. 
Palabras claves: historia; rituales de inclusión; medidas de compensación; amnistía; Mario Echandi Jiménez; Rafael Ángel Calderón Guardia; Nicaragua.

\begin{abstract}
This article establishes that during the government of Mario Echandi Jiménez (1958-1962) a process of national conciliation took place. This process is analyzed through the implementation of what we called «compensation measures» and "political rituals of inclusion», which endorsed the 1948 civil war's losers. For example, the return of Rafael Angel Calderón Guardia and the declaration of a second amnesty for all those linked to the war. As a conclusion, the national conciliation process was also favored by the intensification of the opposition movement to the Somoza dictatorship, as this generated a new configuration of the «enemy» characterizing him as a foreigner, which in turn promoted internal unity.
\end{abstract}

Keywords: history; rituals of inclusion; compensation mesuares; amnesty; Mario Echandi Jiménez; Rafael Ángel Calderón; Nicaragua.

Resumo: Este artigo afirma que durante o governo de Mario Echandi Jiménez (1958-1962) ocorreu um processo de conciliação nacional, que é analisado através da implementação do que denominamos «medidas compensatórias»e «rituais políticos de incluso», que favoreceu aos perdedores da guerra civil de 1948. Por exemplo, o retorno de Rafael Ángel Calderón Guardia à Costa Rica e a declaração de uma segunda anistia para todos os vinculados à guerra. Por fim, conclui-se que o processo de conciliação nacional também veu-se favorecido pela intensificação do movimento de oposição à ditadura de Somoza, pois isso gerou uma nova configuração do «inimigo» caracterizando-o como estrangeiro, o que por sua vez promoveu a unidade interna.

Palavras chaves: história; rituais de inclusão; medidas de compensação; anistia; Mario Echandi Jiménez; Rafael Ángel Calderón Guardia; Nicarágua.

Diez años de sufrimiento nos han dado a todos madurez política... Corina Rodríguez ${ }^{1}$

\title{
Introducción
}

La amnistía de 1955 sentó un importante precedente al marcar el inicio de una nueva etapa en las relaciones políticas de los enemigos de la guerra civil de 1948. Dicha legislación fue el resultado de más de siete años de peticiones y proyectos de ley presentados por diversas agrupaciones políticas y de la sociedad civil, quienes la consideraban necesaria para alcanzar la conciliación nacional e institucionalizar el olvido de la violencia política que había fragmentado a la sociedad costarricense. ${ }^{2}$ No obstante, el proceso de conciliación nacional no

2 Alexia Ugalde, «"Purificarse en las aguas del Jordán”. La ruta política y social de la amnistía de 1955 en Costa Rica y la participación de las mujeres», Diálogos Revista Electrónica de Historia, CIHAC-UCR, 
puede reducirse a la aprobación de dicha legislación. Por ello, en este trabajo se entiende la conciliación nacional como un proceso desarrollado durante la posguerra costarricense y que tuvo como resultados la primera declaración de amnistía en 1955; así como una serie de rituales políticos, durante el gobierno de Mario Echandi Jiménez, que reconfiguraron las relaciones políticas de los grupos que se identificaban como enemigos, mediante dos aspectos, la renuncia a la vía armada como mecanismo de enfrentamiento y acceso al poder, y el traslado del conflicto político al ámbito electoral.

De tal forma que, este artículo tiene por objetivo analizar los rituales políticos que contribuyeron al olvido de la violencia política, los rituales de inclusión que generaron un ambiente de estabilidad que propició, por ejemplo, el regreso de Rafael Ángel Calderón Guardia al país y las medidas de compensación que contribuyeron al reconocimiento de los vencidos como sujetos políticos, lo cual significó su «reincorporación» a la sociedad costarricense. Además, por último, se analiza el papel de Nicaragua y particularmente, el enfrentamiento a la dictadura somocista como un factor externo que impulsó el proceso de conciliación nacional.

Se consultaron documentos del Archivo Nacional de Costa Rica (ANCR) específicamente de los fondos del Ministerio de Gobernación, el Ministerio de Economía y Comercio y el Ministerio de Seguridad Pública. Además, se revisaron discursos presidenciales y prensa nacional, principalmente: La Nación, La Hora, La República y el semanario comunista Adelante. Por último, una fuente considerada de relevancia fue la Colección de Leyes y Decretos de los años 1958, 1959 y 1962, pues permitió identificar la legislación creada como parte de los mecanismos de compensación para los perdedores de la guerra civil de 1948 y de los esfuerzos por encaminar el proceso de conciliación nacional.

\section{Antecedentes}

En las elecciones presidenciales de 1958 el abstencionismo alcanzó el $32,3 \%$, en ese contexto, Mario Echandi Jiménez, candidato del Partido Unión Nacional (PUN), obtuvo el triunfo electoral. Algunos factores alrededor de esta victoria fueron el apoyo del Partido Republicano Nacional (PRN), cuyo primer candidato a diputado por San José era Rafael Ángel Calderón Guardia, quien a diez años de la Guerra Civil de 1948 se encontraba exiliado en México. Además, el Partido Liberación Nacional (PLN) había sufrido una fragmentación debido a la salida de Jorge Rossi, quien fundó el Partido Independiente (PI). De esta forma, el traspaso de poderes, como ritual político, marcó la salida de José Figueres Ferrer y de los vencedores del Ejecutivo, mientras que el nuevo

vol. 21, n. ${ }^{\circ} 1$ (enero-junio, 2020): 37-66, https://doi.org/10.15517/dre.v21i1.38244. 
gobierno representó la llegada de un político vinculado de manera indirecta con el conflicto bélico de 1948.

De hecho, Echandi representaba a una víctima más de la violencia política ejercida por los vencedores pues, en febrero de 1955, junto al diputado Guillermo Jiménez Ramírez, había sufrido la expulsión de la Asamblea Legislativa y la suspensión del ejercicio de su cargo luego de ser acusados de traición a la patria, sedición, rebelión y complicidad con el sector que invadió el el territorio costarricense ese mismo año. Como muestra de apoyo, la minoría legislativa decidió dejar sus labores durante ocho meses. ${ }^{3}$ En su discurso de defensa, el diputado Jiménez Ramírez denunció: «Pueden ustedes levantarme la inmunidad, pueden encarcelarme y cebarse en mí, que yo en eso solo veré la continuación de la persecución del figuerismo contra sus oponentes». ${ }^{4}$

Finalizada dicha sesión parlamentaria, Echandi fue perseguido por un grupo de gobiernistas deseosos de causarle daño, hasta el Club Unión donde se resguardó. Días después, el 3 de febrero de 1955, su oficina fue incendiada junto a un depósito de madera de su propiedad, afectándose también un taller de ebanistería contiguo. ${ }^{5}$ Este incidente fue recordado en 1959 por el mismo Echandi con las siguientes palabras: «...de todos los escombros, el pueblo me sacó y hoy me tiene en la Presidencia». ${ }^{6} \mathrm{Al}$ respecto, Charles Ameringer, apuntó que Echandi «pasó de ser un político con pocos seguidores a convertirse en un héroe de las fuerzas antifigueristas». ${ }^{7}$ Sin duda, en esta transformación tuvieron gran importancia los ataques contra él, pues lo acercaron a los sectores perdedores de la Guerra Civil de 1948.

\section{La llegada de Mario Echandi Jiménez a la presidencia}

En 1958 se conmemoró el décimo aniversario de la Guerra Civil, coincidiendo con el inicio del gobierno de Echandi. La prensa informó de actividades organizadas por la Asociación Nacional de Ex-combatientes (ANE) para conmemorar lo que llamaban la «Gesta Libertadora». ${ }^{8}$ Ese año se caracterizó por un claro giro en los discursos sobre el conflicto bélico, lejos de fomentarse la

3 David Díaz Arias, Crisis social y memorias en lucha: guerra civil en Costa Rica, 1940-1948 (San José, Costa Rica: EUCR, 2015), 317. Según Kirk Bowman, en 1954 era claro que Picado, Calderón, Echandi, Castro Cervantes y Ulate estaban de acuerdo qué medios no democráticos deberían ser usados para deshacerse de Figueres y salvar al país del socialismo. Ver: Kirk Bowman, «¿Fue el compromiso y consenso de las élites lo que llevó a la consolidación democrática en Costa Rica? Evidencia de la década de 1950», Revista de Historia, n. 41 (enero-junio, 2000): 105, https://www.revistas.una.ac.cr/index.php/historia/ article/view/1868/1772.

4 La Nación, «Suspendidos dos diputados en sus funciones», 2 de febrero de 1955, 14.

5 La Nación, «A punto de ser linchado el Dip. Echandi...», 2 de febrero de 1955, 5 y La Nación, «Incendio en la oficina...», 4 de febrero de 1955, 8.

6 La Nación, «Yo sé que la paz asfixia...», 4 de marzo de 1959, 1.

7 Charles Ameringer, Don Pepe: A Political Biography of José Figueres of Costa Costa Rica (México, D.F.: University of New Mexico Press, 1978), 127.

8 La Hora, «Conmemoración de la lucha armada del 48», 7 de abril de 1958, 8. 
división política o el enfrentamiento, aparecen llamados a la conciliación nacional desde los sectores otrora enemigos. Por ejemplo, el 1 de mayo de 1958, Francisco Calderón Guardia quien, como su hermano, había sido electo diputado, fue acompañado a la Asamblea Legislativa por un grupo de calderonistas que intentaron alzar en hombros, pero él se negó. Luego, lo siguieron hasta la casa de Jorge Alvarado Piza, donde pronunció algunas palabras asegurando haber iniciado «una nueva etapa política de actividades en el orden civil en donde debe imperar la sensatez, la serenidad y naturalmente el respeto a quienes son adversarios políticos». Además, recordó el próximo regreso al país de su hermano e instó a no caer en provocaciones durante su recibimiento para evitar resentimientos en quienes tenían «el derecho a sustentar ideas políticas contrarias». ${ }^{9}$

Lo más sorprendente de este discurso de Francisco Calderón es que él estuvo activamente involucrado en las invasiones de diciembre de 1948 y enero de $1955,{ }^{10}$ por lo que su ocupación de un cargo legislativo puede interpretarse como su renuncia a la violencia política. Asimismo, representaba el reconocimiento social de los calderonistas como sujetos políticos, es decir, como ciudadanos. Sin duda, estos eran elementos introductorios de una nueva etapa política, que había sido anunciada como un objetivo común desde la campaña electoral de 1958, la cual, según Manuel Gamboa, tuvo por tema ¿quién podría lograr la reunificación de la familia costarricense? ${ }^{11}$ Por mencionar unos ejemplos, en un afiche electoral para Golfito, el candidato a diputado Edgar Chaverri y Echandi son llamados «los hombres honestos de la unificación nacional». ${ }^{12}$ Mientras que los resultados de las elecciones son interpretados por el Comité de Radio y Prensa del PRN, de la siguiente manera: «El país dijo en las elecciones pasadas que está cansado de que se insista en remover pasiones. El pueblo se pronunció en favor de la conciliación y la unificación de la familia costarricense [...] Costa Rica ha entrando en una nueva era de su vida». ${ }^{13}$

La idea de que la llegada de Echandi representaba el inicio de un gobierno de unidad nacional fue cobrando cada vez más fuerza. Como se puede observar

9 La Nación, «En medio de un escándalo inauguró sus sesiones...», 3 de mayo de 1958, 12 y La Nación, «No viene a hacer política ni a cobrar agravios», 6 de mayo de 1958, 50.

10 Para profundizar en el tema de las invasiones ver: Alexia Ugalde, «"Caínes despiadados... Caínes invasores”. La invasión del 10 de diciembre de 1948 a Costa Rica en perspectiva nacional y transnacional», Anuario de Estudios Centroamericanos, n. ${ }^{\circ} 46$ (2020): 1-33, https://doi.org/10.15517/aeca.v46i0.42206 y Alexia Ugalde, «Nicaragua y la invasión de 1955 en los discursos de la prensa costarricense», Anuario de Estudios Centroamericanos, n. ${ }^{\circ} 42$ (2016): 295-325, https://doi.org/10.15517/aeca.v42i1.26951.

11 Manuel Gamboa, Los discursos políticos durante las campañas electorales entre 1953 y 1970 en Costa Rica: la memoria de la Guerra Civil de 1948 (Tesis de Licenciatura en Historia, Universidad de Costa Rica, 2012), 103-104 y 108-110, http://www.kerwa.ucr.ac.cr/bitstream/handle/10669/853/Tesis\%20\%20 de\%20Historia\%20-Manuel\%20Gamboa.pdf?sequence=1\&isAllowed=y.

12 Archivo Nacional de Costa Rica (ANCR), Material Divulgativo de Pequeño Formato (MADIPEF), 1201, f.1.

13 La Nación, «Comité de radio...», 11 de noviembre de 1958, 16. 
en un mensaje de Karen Olsen Beck, primera dama del período 1953-1958, transmitido en cadena de radioemisoras el 6 de mayo de 1958:

\begin{abstract}
Dios quiera que en nuestra patria no se vuelva a interrumpir la paz, ni el orden constitucional. Que las diferencias de criterio político, propias del sistema democrático, se discutan entre caballeros y entre damas dentro de un espíritu de unidad nacional [...] El régimen que surgió del sacrificio de 1948 dio el voto a las mujeres. Sepamos usar ese derecho... ${ }^{14}$
\end{abstract}

Su renuncia pública a la vía armada pudo estar mediada por la incorporación de los hermanos Calderón en las elecciones nacionales como mecanismo para acceder al poder y su alineamiento con Echandi, muestra de que compartían su promesa de campaña sobre la conciliación nacional. El 1 de mayo de 1958 Francisco Calderón declaró: «Vamos a dar, sin regateos o titubeos, toda la colaboración que nos sea posible ofrecer a los propósitos de unificación nacional que persigue el señor Presidente electo...». ${ }^{15}$ Posteriormente, Francisco Montero Madrigal, representante del PRN confirmaría dicha idea: «El Partido Republicano acogió la tesis de la conciliación nacional que llevó al triunfo de la candidatura del licenciado don Mario Echandi Jiménez»». ${ }^{16}$

\title{
El traspaso de poderes
}

El 8 de mayo de 1958, con el traspaso de poderes, inició un nuevo período en las relaciones políticas de los bandos enfrentados durante la Guerra Civil de 1948. Para demostrar que discursivamente hubo un giro orientado a la conciliación nacional, se analizaron las declaraciones emitidas por representantes de diversos sectores. Por ejemplo, de Figueres Ferrer, Echandi, el PRN, Manuel Mora y la iglesia católica. Para comenzar, Figueres se refirió a la reincorporación de los calderonistas en la participación electoral como una señal de constante cambio en la sociedad costarricense. Ante ello afirma:

\footnotetext{
Nuestra libertad electoral es tan completa, que el grupo vencido en varios choques armados en los últimos 10 años, lleva ahora a la Asamblea Legislativa, legítimamente, un número tal de diputados que ocupa el segundo puesto en las fuerzas parlamentarias [...] Yo deseo que con esta jornada cívica termine la división que nos dejó la Guerra de Liberación Nacional de 1948. Después de una guerra entre hermanos, cuando todos han alcanzado la plena libertad, y el amplio disfrute de sus derechos ciudadanos, no hay razón para que el odio continúe. Menos aún, para que ese odio se transmita a la generación siguiente [...] ya se ha vertido suficiente sangre para lavar todo pecado [...] Necesitamos cordura, olvido y perdón, recíprocamente, paz y unión... ${ }^{17}$
}

17 José Figueres Ferrer, «Traspaso de poderes», Mensajes Presidenciales 1940-1058, T. VII, ed. Carlos Meléndez (San José: Imprenta Nacional, 1990), 466. 
Según David Díaz, este discurso de Figueres mostraba un importante cambio pues «La misma persona que hizo esfuerzos por convencer a la oposición al calderonismo de que una guerra era la única forma en la que podría deshacerse de sus enemigos, ahora promovía la unidad». ${ }^{18} \mathrm{Al}$ igual que el conflicto bélico fue representado como un sacrificio doloroso, pero necesario, ahora, el olvido se convirtió en el nuevo sacrificio. Sin embargo, esta narrativa de la conciliación era selectiva con los hechos pasados, pues omitía la violencia política y la persecución ejercida por los vencedores durante la posguerra costarricense, así como su relación con la permanencia de la inestabilidad política. Así, equiparar «los pecados» cometidos por ambos bandos hacía posible el perdón y el olvido.

Por otra parte, Echandi se presentó como el político cuya responsabilidad era guiar el proceso de conciliación nacional diciendo: «No serviré intereses de bandera política, ni clase económica o social [...] vibra, en lo más íntimo de mi ser, el fervoroso anhelo de poner término a todas las disensiones políticas que han mantenido división en el seno del país, y de hacer de Costa Rica una sola patria...». ${ }^{19}$ El líder comunista Manuel Mora, en representación del sector más afectado por la violencia política de la posguerra costarricense, destacó dos asuntos positivos de las declaraciones hechas por Echandi: «su propósito de hacer respetar las libertades públicas sin discriminaciones para nadie y su ofrecimiento que nos parece sincero, de tratar de buscar una política capaz de garantizarle bienestar al pueblo. Dentro de esta línea pide colaboración a todos los costarricenses. Es justo que se le de esa colaboración....». ${ }^{20}$

Por su parte, el PRN emitió un mensaje refiriéndose a la toma de posesión de Echandi con las siguientes palabras: «Este acto, culminación de una lucha en la que el PARTIDO REPUBLICANO tuvo una participación decisiva, nos hace sentir que por fin, Costa Rica entrará en una etapa de verdadera reconciliación; de orden, paz y trabajo para todos». ${ }^{21}$ Mientras que Monseñor Rubén Odio Herrera, Arzobispo de Costa Rica, declaró: «Mucho nos complace afirmar que la iglesia abunda en los mismos propósitos de concordia y unión nacionales y que gustosa colaborará por los medios de que dispone, para verlos hechos realidad...». ${ }^{22}$ De manera que, distintos sectores coinciden en que inicia una nueva etapa para el país que rompería con el pasado cercano de la guerra mediante la unidad, el olvido y el perdón.

Como parte de los rituales políticos, Echandi anunció que al finalizar el traspaso de poderes ofrecería en la Casa Amarilla una recepción para el «pueblo

18 Díaz Arias, Crisis social y memorias en lucha..., 320.

19 Mario Echandi Jiménez, Discurso del traspaso de poderes, 8 de mayo de 1958, en: https://docs.google. $\mathrm{com} /$ viewer? $\mathrm{a}=\mathrm{v} \&$ pid=sites\&srcid=ZGVmYXVsdGRvbWFpbnxtZW5zYWplcHJlc21kZW5jaWFsY3J8Z3g6NGExZmMwZGQzY2Q3MTljOQ.

20 Adelante, «Sensacional discurso...», 4 de mayo de 1958, 4.

21 La Nación, «Partido Republicano», 8 de mayo de 1958, 4.

22 La Nación, «Agradezcamos al Señor esta bendición...», 9 de mayo de 1958, 1 y 7 .. 
de Costa Rica», sin distinciones de tipo político ni de clase social. El periódico La Nación confirmó que en dicha actividad participaron grupos políticos que apoyaban al nuevo presidente, pero también «muchos» liberacionistas, esto se interpretó como una muestra de que: «...se está produciendo realmente la unión de la familia costarricense, reanudándose la convivencia amistosa entre todos los ciudadanos...»». ${ }^{23}$ Precisamente, esta celebración simbolizaba su compromiso con lo que denominaba el gobierno de unidad nacional. Aunado a esto, se debe señalar que la Asamblea Legislativa había quedado compuesta por tres tendencias igualmente fuertes, por tanto, ninguno de los partidos contaba con suficientes diputados como para constituir la mayoría.

\section{Relación con la Asamblea Legislativa}

Al inicio del gobierno de Echandi hubo un claro intento por evitar los enfrentamientos políticos, como parte del compromiso que diversas tendencias habían asumido con la conciliación nacional. No obstante, una pequeña fracción dentro de la Asamblea Legislativa representada por José Cordero Croceri, José Vega Rojas y Roberto Losilla Gamboa empezó a cuestionar al gobierno de Echandi, asegurando que se escudaba en la tesis de conciliación nacional para restringir el derecho de la oposición a criticarlo:

\footnotetext{
Nuestro objetivo era desenmascarar lo que se ha dado en llamar «conciliación nacional», a la que, todos los altos funcionarios del actual régimen recurren en forma constante. Esto lo vemos corrientemente en los debates en la actual Cámara Legislativa. Los diputados gobiernistas para refutar a un representante de otra fracción que hace una crítica al Gobierno, a falta de argumentos, le acusan de poner en peligro la tesis de «conciliación nacional». ${ }^{24}$
}

En agosto de 1958, se informó en la prensa sobre una reunión que tendría Echandi con el presidente de la Asamblea Legislativa, Álvaro Montero Padi1la, pues parecía existir un ambiente de tensión entre ambos poderes. ${ }^{25}$ Además, participaron algunos diputados como Frank Marshall, ${ }^{26}$ con quien Montero hizo «remembranza de nuestros años de colegio donde juntos habíamos convivido años inolvidables en el Liceo de Costa Rica [...] para ir aflojando la tensión que en ese momento prevalecía, por lo menos ante el país, entre los dos Poderes». ${ }^{27}$ En una segunda reunión, se consideró indexar una comisión de diputados de todos los partidos, su responsabilidad era velar por el alejamiento de los temas que podían avivar las pasiones políticas. No obstante, el diputado Enrique

23 La Nación, «Magnífico espectáculo», 9 de mayo de 1958, 25.

24 La República, «Es una farsa la conciliación nacional», 29 de mayo de 1958, 12-13.

25 La Nación, «Antes que todo, buscar fórmulas..., 9 de agosto de 1958, 31.

26 Frank Marshall había sido electo diputado por el partido antifiguerista y de ultraderecha «Unión Cívica Revolucionaria», el cual había fundado. Ver. Bowman, 2000, p. 113.

27 La Nación, «Reveladas intimidades de la entrevista...”, 14 de agosto de 1958, 14. 
Obregón Valverde se opuso tras señalar que la tesis de conciliación era un vacío epistemológico por parte de quienes habían llegado al gobierno y no podían liderar por ellos mismos. ${ }^{28}$ En respuesta, el diputado Fernando Lara Bustamante aseguró que la tesis de conciliación nacional:

[...] respondió a un anhelo nacional, de casi todos los partidos, pues todos en su propaganda, ofrecían esforzarse en lograr la unidad de la familia costarricense [...] no significa incapacidad para gobernar, ni menos desorientación concreta y definida hacia una meta de bien público; acabar con las hondas divisiones y con las pasiones políticas. ${ }^{29}$

Por su parte, Ángela Acuña, fundadora de la Liga Feminista en Costa Rica, también aprovechó el debate generado en la Asamblea Legislativa para convocar a la unidad nacional, diciendo: «Aprovechemos la era de paz que se ofrece a manos llenas [...] Unámonos en el afán de engrandecer la tierra de nuestros mayores, en la acción civilizatoria de olvidar rencillas y desterrar caprichos». Además, se refirió a Echandi como un «noble visionario que se esfuerza, sin ambiciones personales, ni codicia alguna, en señalar una nueva era para Costa Rica» ${ }^{30}$ Finalmente, en declaraciones de Echandi se identificó a Francisco Orlich, Bolmarcich ${ }^{31}$ como el mayor oponente de la conciliación y la paz en el país debido a su renuncia al diálogo:

Jamás imaginé que tan hábil y distinguido político optara por dar al país la evidencia de que a él no le interesa la paz de la república, ni le preocupa llegar a la armonía deseada entre las distintas tendencias para bien de la patria [...] continuaré haciendo cuantos esfuerzos estén a mi alcance por lograr la armonía de todas las fracciones políticas [...] Juzguen los costarricenses los hechos en la seguridad de que nada me detendrá en mi afán de lograr para ellos la paz en que creo y la armonía que, por tenérselas prometidas, merece mis mayores esfuerzos. ${ }^{32}$

La promesa de campaña de Echandi de trabajar por la conciliación nacional tenía el apoyo, en primer lugar, de un amplio sector de la sociedad que había decidido votar por él, como una forma de manifestar su deseo de que acabara la fragmentación producto de la división política y la Guerra Civil de 1948 y segundo, por un sector del Poder Legislativo que pertenecía a otros partidos políticos, pero había acordado que Echandi fuera el candidato a la presidencia del Movimiento Democrático Oposicionista (MDO) ${ }^{33}$ Sin embargo, existía una

28 La Nación, «Otro debate político», 2 de setiembre de 1958, 1 y 9.

29 La Nación, «Se encendió el debate político...», 3 de setiembre de 1958, 38.

30 La Nación, «Hagamos patria», 26 de agosto de 1958, 4.

31 Por el contrario, Bowman señala que cuando Figueres estaba dispuesto a no aceptar los resultados de las elecciones de 1958, el único que fue capaz de convencerlo de que era una locura, fue el candidato derrotado, Orlich. Ver: Bowman, 115.

32 La Nación, «Para lograr la paz y la armonía...», 27 de agosto de 1958, 9.

33 Bowman, p. 113. 
pequeña fracción de la oposición liberacionista que consideraba que el discurso de la conciliación era una mampara para ocultar la incapacidad de Echandi para dirigir el país.

\section{El regreso de Rafael Ángel Calderón Guardia}

Después de diez años de permanecer en el exilio, en 1958 regresaron los hermanos Calderón Guardia. El 26 de abril llegó Francisco, pues formaría parte de la nueva Asamblea Legislativa como representante del PRN y el 8 de junio regresó Rafael Ángel, para este último, se organizó El Desfile de la Concordia Nacional. Según informó la prensa, un grupo de amigos se organizaron para viajar a la Ciudad de México y regresar con el Doctor en el mismo avión, quienes estuvieran interesados en acompañarlos debían ir al local del partido. ${ }^{34}$ Aún estando en México, a 15 días de su regreso, Calderón dio un mensaje por radio, haciendo referencia a las pasadas elecciones, a las heridas dejadas por la Guerra Civil y por la violencia de la posguerra y asegurando que el apoyo a Echandi respondía a su intención de unificación nacional:

Unidos todos bajo el propósito común de que la Patria, que vuelve a ser la Patria de todos, sane de las heridas de los últimos diez años de enconada lucha... Ahora estamos empeñados todos en que los propósitos de Conciliación Nacional que nos llevaron a votar por el actual Presidente de la República Licenciado Echandi, se conviertan en una hermosa realidad [...] el país se pronunció en favor de la tesis de la Unificación Nacional [...] PERDÓN Y OLVIDO [...] ORDEN Y PAZ para que Costa Rica vuelva a ser la Patria de todos... ${ }^{35}$

El 26 de mayo de 1958 se informó sobre la llegada de Calderón a Nicaragua, en compañía de un «numeroso grupo de amigos y allegados», además se señaló la salida de «muchos» costarricenses hacia Nicaragua por tierra, con el propósito de encontrarse con el Doctor. ${ }^{36}$ Por otra parte, Graciela Morales de Echeverría, presidenta del Comité organizador del desfile, dirigió el 29 de mayo una carta al Ministro de Gobernación, Joaquín Vargas Gené, solicitando la autorización para llevar a cabo dicho evento, describiéndolo como:

[...] un acto cívico libre de resentimientos, de malquerencias y sobre todo cualquier cariz político [...] han de concurrir amigos de todas partes del país y a quienes hemos dado instrucciones para que su comportamiento sea de acuerdo con el homenaje de amistad que se desea rendir... ${ }^{37}$

34 La Hora, «Conferencia Echandi Jiménez-Calderón Guardia», 29 de abril de 1958, 1 y 8; La República, «Pedido el permiso para el recibimiento...», 22 de mayo de 1958, 10.

35 La Nación, «Partido Republicano», 25 de mayo de 1958, 16.

36 La Hora, «Calderón Guardia llegó a Nicaragua», 26 de mayo de 1958, 1.

37 La Nación, «Arreglada organización del recibimiento...», 1 de junio de 1958, 4. 
La respuesta del ministro fue positiva, autorizando el ritual político para recibir al caudillo. Sin embargo, se establecieron algunas restricciones, por ejemplo, se prohibió llevar banderas del partido, estas tuvieron que entregarse al ministerio y luego del desfile serían devueltas. También, Vargas Gené se reunió previamente con calderonistas y excombatientes, entre ellos, Marshall, Francisco Calderón y Figueres. Además, se aplicó ley seca desde las once horas de la noche anterior y se colocó vigilancia para controlar las calles y avenidas adyacentes al aeropuerto de La Sabana. ${ }^{38}$ Estas medidas respondían a la oposición al regreso de Calderón por parte de un sector de los excombatientes de la Guerra Civil. Incluso, surgió la inquietud ante la posibilidad de que se desatara otro episodio de violencia política. El 1 de mayo de 1959, casi un año después, Echandi dijo en su su discurso: «En los días en que se anunciaba el regreso del doctor Calderón Guardia, voceros de los grupos políticos antagónicos levantaban sus voces airadas y hacían pensar en situaciones inciertas y peligrosas»». ${ }^{39}$

\title{
La oposición de la Asociación Nacional de Excombatientes (ANE)
}

Los excombatientes que se opusieron al recibimiento público de Calderón formaban parte de la Asociación Nacional de Excombatientes (ANE). El mes anterior al regreso de Calderón, esta agrupación activamente manifestó en la prensa nacional los peligros que podrían desencadenarse con la llegada del caudillo y con su recibimiento público y masivo. Los principales argumentos utilizados para incentivar la censura de dicha manifestación fueronlas memorias de las víctimas de los diversos enfrentamientos y el recuerdo de los actos de violencia dirigidos por los calderonistas, especialmente, las dos invasiones:

\begin{abstract}
Preparan carrozas, carteles y fanfarrias, para recibir a su jefe... En diciembre de 1948, con sacrificios de ciudadanos distinguidos por su posición de preeminencia social e intelectual, hubo que volver a detenerlo. Por último, en 1955, cuando Costa Rica vivía un clima de absoluta libertad y plenas garantías, intentó de nuevo volver a apoderarse, ilegalmente, del poder público [...] Ante esta situación y sin poder olvidar que el grupo político del Sr. Calderón cometió en Costa Rica, a lo largo de muchos años, actos reprochables e inmorales que en muchos casos constituyen acciones de bandolerismo puro, la mayoría de los costarricenses se siente justamente preocupada de lo que podrá suceder ese día o en días posteriores... ${ }^{40}$
\end{abstract}

Asimismo, para demostrar la ilegitimidad del evento utilizaron la memoria de los caídos, como recordatorio de los «sacrificios» realizados, los cuales no debían olvidarse:

38 La Nación, «Fueron tantos... que es imposible decir cuántos...!», 12 de junio de 1958, 24-25 y La Hora, «Concentrada la fuerza pública», 7 de junio de 1958, 1.

39 Mario Echandi Jiménez, Discurso presentado ante la Asamblea Legislativa, 1 de mayo de 1959, en: https://docs.google.com/viewer?a=v\&pid=sites\&srcid=ZGVmYXVsdGRvbWFpbnxtZW5zYWplcHJlc2lkZW5jaWFsY3J8Z3g6ZDFmNTViMzZmNGJhNDdl.

40 La República, «A los costarricenses», 1 de mayo de 1958, 8. 


\begin{abstract}
Muchas han sido las vidas, mucha la sangre, muchas las lágrimas y el dolor, que el nombre del Sr, Rafael A. Calderón ha costado a Costa Rica. En nombre de todos los compañeros caídos, esta Asociación, vigilante de que su sacrificio no se convierta en estéril, denuncia el acto de recibimiento del Sr. Calderón Guardia, como una manifestación política expresamente prohibida por la ley... ${ }^{41}$
\end{abstract}

Estos excombatientes no se oponían al regreso de Calderón al país, sino al acto público organizado para su recibimiento, pues lo consideraban una manifestación de carácter político. El sustento legal utilizado por la ANE fue el artículo 26 de la Constitución Política y el artículo 79 del Código Electoral, en los cuales existían disposiciones sobre las manifestaciones y desfiles políticos, siendo permitidos solamente durante los dos meses anteriores a una elección. ${ }^{42}$ Como respuesta, el Comité organizador del desfile se dirigió a los excombatientes asegurando que:

No puede ser un acto político, puesto que el período en que la ley permite manifestaciones de esa clase terminó. La campaña política terminó también cuando el pueblo dijo en las urnas el dos de Febrero, que deseaba el poder para el partido que había levantado la bandera de la UNIFICACIÓN NACIONAL. ${ }^{43}$

Asimismo, la ANE envió una carta al Ministro Vargas Gené, exponiendo «la honda preocupación» que sentían por el mantenimiento de la paz, de la concordia y de la armonía en toda la República ${ }^{44} \mathrm{~A}$ lo cual el ministro respondió que la autorización que había dado se reducía al permiso de entrar al aeropuerto con el fin de saludar a Calderón y luego acompañarlo a su casa de habitación. Aprovechando la comunicación de la ANE para decirles: «estoy seguro de que por el interés nacional, no negarán la colaboración que con la mayor vehemencia les pido para que entre todos logremos mantener la paz y tranquilidad nacionales». ${ }^{45}$

A pesar de que, el 30 de mayo de 1958, tuvieron una reunión con el Ministro de Gobernación, lo cual demostraba su influencia y lo efectiva que había sido su estrategia de recordar la violencia política, para sembrar la inquietud, continuaron insistiendo en la necesidad de prohibir el desfile pues podía desencadenar «desórdenes de consecuencias imprevisibles». ${ }^{46}$ En apoyo en un Editorial del periódico La República afirmó:

La Asociación Nacional de Ex-combatientes tiene de su parte la razón y la ley. Es inconveniente y es ilegal que la llegada de un político a Costa Rica se preste para realizar manifestaciones que implican una provocación y que pueden ser fuente de desórdenes de imprevistas consecuencias. Los excombatientes han cumplido con

41 Ibíd.

42 La República, «Asociación de excombatientes...», 24 de mayo de 1958, 1 y 20.

43 La Nación, «ORDEN Y PAZ», 27 de mayo de 1958, 18.

44 La Hora, «Ninguna resolución del gobierno...», 28 de mayo de 1958, 1.

45 La Nación, «Si todos miramos el interés nacional...», 25 de mayo de 1958, 70.

46 La Hora, «Ninguna resolución del gobierno...», 1. 
su deber cívico de indicarle al Poder Ejecutivo los riesgos que pueden existir de permitirse un acto que se encuentra al margen de la ley. ${ }^{47}$

Por otra parte, los comunistas consideraban que los calderonistas tenían derecho a recibir a su líder político, tal como lo habían hecho los figueristas cuando su caudillo regresó del exilio en México y desfilaron por la Avenida Central sin que el gobierno de Teodoro Picado les opusiera ningún obstáculo. Por lo que denunciaron:

Los ex-combatientes figueristas han reaccionado mal. Han tomado el recibimiento del Dr. Calderón Guardia como una provocación a ellos y amenazan con promover violencias... El Dr. Calderón Guardia cambiando radicalmente su vieja línea, ha dicho en su último discurso que viene decidido a colaborar en una política de unidad nacional [...] tiene el propósito de fomentar la tranquilidad pública y de desarrollar su lucha dentro de los cauces de la Constitución y de las leyes. Tal actitud nos parece positiva. Así las cosas nos parece que los excombatientes no podrían en ninguna forma justificar cualquier agresión a los calderonistas. ${ }^{48}$

Ante la inquietud sobre la forma en que podían actuar los excombatientes y la posibilidad de que lo hicieran de forma violenta, el mismo editorial de $L a$ República citado anteriormente, le pedía a la ANE:

Dejar en manos del Gobierno la solución del asunto, y acatar el acuerdo que se tome. Si la disposición ejecutiva es la de conceder de todas maneras el permiso, lo aconsejable es que cada cual se mantenga en sus actividades ordinarias, sin tratar de agruparse para impedir que la manifestación se realice. Es bueno darle al país una prueba más de cordura, de civismo, de madurez de juicio y aún de elegancia ciudadana [...] Si el político ese quiere violar la ley, como su primer acto en Costa Rica, allá él. La gente de bien debe permanecer tranquila... ${ }^{49}$

El día antes de la llegada al país de Calderón, en La Nación se aseguró que «los sectores políticos antagónicos [...] han contestado a las autoridades competentes que, aun sin abandonar su punto de vista que considera ilegal la actividad anunciada, no harán cosa alguna capaz de comprometer el orden y la tranquilidad...». ${ }^{50}$ Por su parte, quienes organizaron el desfile hicieron un llamado a la prudencia a quienes estarían en La Sabana: «quien haga algo inconveniente es bueno decirlo ahora y repetirlo: podrá ser cualquier cosa, menos un soldado del Partido Republicano y nunca un amigo de Calderón Guardia». ${ }^{51}$ De esta forma, a pesar de las tensiones políticas, representantes de los bandos enfrentados durante la guerra civil se comprometieron a no generar episodios de violencia.

47 La República, «Con los excombatientes», 28 de mayo de 1958, 6.

48 Adelante, «Si los excombatientes promueven...», 1 de junio de 1958, 1 у 6.

49 La República, «Con los excombatientes», 6.

50 La Nación, «Apelación a la prudencia», 7 de junio de 1958, 6.

51 La Nación, «A la sabana», 27 de mayo de 1958, 14 y La Nación, «A las 10...», 30 de mayo de 1958, 8. 


\section{A su encuentro}

El 8 de junio de 1958, Calderón regresó a Costa Rica y una gran cantidad de personas, desde diversos lugares del país, acudieron a su encuentro en el aeropuerto de La Sabana - ver Imagen 1-. En La Nación se describió la concurrencia como «la masa humana más grande que se ha visto en Costa Rica». ${ }^{52}$ Los calderonistas habían esperado diez años a que su líder pueda volver sin temor a ser tomado preso por los vencedores, por lo que el final del gobierno de Figueres había sido fundamental para su regreso. Sin duda, este ritual político fue el acto público más grande organizado por los calderonistas, quienes por una década habían sufrido la censura, sin duda se estaban transformando las relaciones políticas del país.

\section{Imagen 1. Regreso de Rafael Ángel Calderón Guardia en La Sabana}

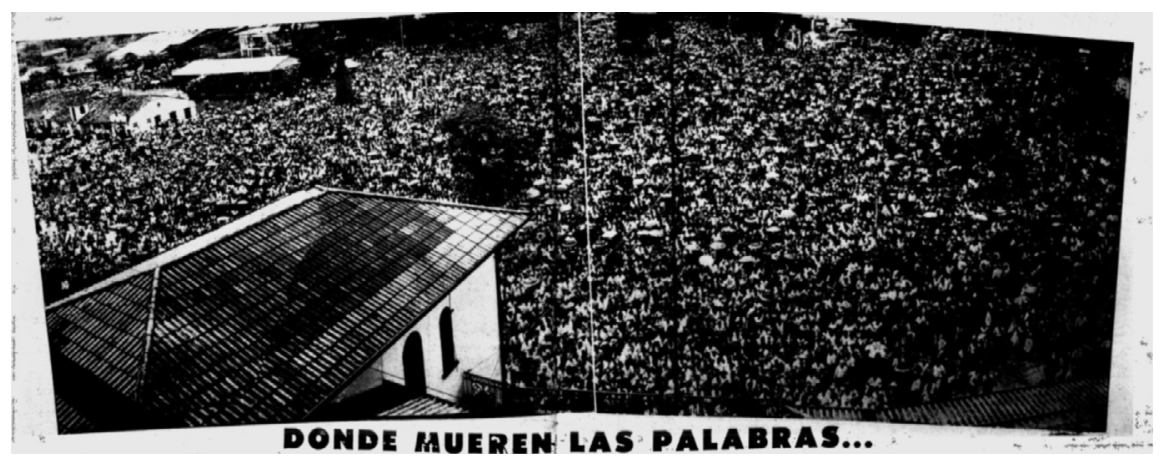

Fuente: La Nación, 12 de junio de 1958, 24-25.

El evento transcurrió sin actos de violencia, tal como se habían comprometido los calderonistas y los excombatientes. Mientras que el discurso de Calderón, como ya lo habían señalado los comunistas, ahora era radicalmente diferente. Por ejemplo, agradeció a sus adversarios políticos por mantener una actitud respetuosa, calificada por él mismo como una aspiración a «superar la etapa política en la que predominaron las pasiones sobre la razón». Además, le atribuyó a todos los costarricenses la responsabilidad de «mantener el ambiente de paz, concordia y de respeto para quienes, en el campo de la política, sustenten una ideología distinta....». ${ }^{53}$

El cambio en los discursos, es decir, el llamado a la conciliación nacional por quienes antes habían perpetuado las hostilidades y el enfrentamiento, así como el regreso de Calderón, propiciaron a su vez, la reflexión sobre las consecuencias de la Guerra Civil de 1948 y sobre la fragmentación de la sociedad

52 La Nación, «Fueron tantos... ...», 24-25.

53 La Nación, «No he venido a hacer política», 10 de junio de 1958, 18. 
costarricense por al menos diez años de posguerra. Surgieron interpretaciones sobre el regreso de Calderón como el evento que iniciaba una verdadera etapa de conciliación nacional, adjudicándose a la sociedad en su conjunto, y no a actores específicos, los horrores de la guerra Es probable que este proceso contribuyera a darle paso al olvido. Por ejemplo, en un Editorial de La Nación se planteó:

El hecho evidente de que no sucediera nada anormal ha venido a ratificar la naciente confianza en el espíritu nuevo [...] Pareciera que hubiera sido necesario ese sacrificio de todos, esa angustia de nuestros hogares y ese sacrificio colectivo que tantas vidas y millones nos han costado, para que volviendo los ojos hacia la razón el país enderezara sus pasos y Costa Rica volviera a ser Costa Rica [...] El tiempo es tan buen consejero, lenitivo de todos los pesares y sanador de las heridas, ha hecho reflexionar a todos [...] Que la lección la hayamos aprendido y bien... ${ }^{54}$

Durante 1958, con la victoria electoral de Echandi, se abrió la posibilidad de construir relaciones políticas distintas, que renunciaran al enfrentamiento armado como la vía para acceder al poder, ocupando su lugar el proceso electoral. Parece que a excepción de la ANE, existía un consenso sobre ese nuevo rumbo. Como concluía el mismo Calderón «Acaba de iniciarse un gobierno cuyo programa de conciliación nacional ha encontrado eco favorable en todos los sectores del país, políticos y no políticos». ${ }^{55}$ Es claro también, que el fracaso en las invasiones de 1948 y 1955 había hecho a los calderonistas replantearse sus estrategias políticas.

\section{El atentado a Calderón}

El 13 de julio de 1958, poco más de un mes después del regreso de Calderón, su casa fue ametrallada justo cuando seestaba acompañado por dos familiares. El ataque se llevó a cabo aproximadamente a las 2 de la madrugada y aparentemente se trató de nueve tiros, uno de ellos alcanzó a alojarse en la habitación del Doctor. En la prensa, el acto fue descrito como un atentado. Sin duda, era una manifestación de violencia política que buscaba revivir el conflicto . Como se interpretó en un Editorial de La Nación

[...] la buena estrella que protegió al señor Calderón Guardia protegió la tranquilidad y el orden de nuestro país, y no abrió un paréntesis de nuevas inquietudes en la vida nacional [...] Quiera Dios que este sea el último aleteo del odio bajo nuestro cielo costarricense; que el hecho aislado, quede aislado y sea el punto final de una era lamentable de nuestra historia [...] Olvido y perdón para todas las desventuradas equivocaciones que dieron a nuestra Patria horas dolorosas [...] El país ha entrado francamente por el camino de la razón [...] Los exiliados han

54 La Nación, «Renacimiento», 10 de junio de 1958, 6.

55 La Nación, «No he venido a hacer política», 10 de junio de 1958, 18. 
estado volviendo a sus hogares y flores de reconciliación han brotado por doquier en nuestra Patria. La locura de las obcecaciones fue pasando con gran contento de la mayoría de los costarricenses... ${ }^{56}$

No obstante, por parte de los calderonistas hubo un esfuerzo por despolitizar el ataque, como se puede deducir de sus declaraciones. Al día siguiente del atentado, en una publicación de un vocero de Calderón, se le atribuyó a «cabezas locas». En la misma línea, las declaraciones de Calderón lo describían como:

un acto aislado, del que en forma alguna se puede responsabilizar a ningún grupo o partido político. Lo probable, y más que probable es que los disparos los hicieron dos o tres individuos apasionados y excitados por el licor. Dichosamente para todos los partidos y para el país, hemos superado la etapa política en que imperaba el uso de la violencia. Esa etapa está superada, como digo, y debe ser olvidada, para siempre... ${ }^{57}$

Si bien, hubo un intento por ignorar el contenido político del ametrallamiento a la casa de Calderón y por posicionarlo como un acto aislado; el mismo día, en Heredia se estallaron dos candelas de dinamita, una aproximadamente a las 10 de la noche detrás del Cuartel de dicha ciudad y otra en la entrada de una finca cercana, ocasionándose solamente daños materiales que no eran de consideración. ${ }^{58}$ Indudablemente, estos tres actos de violencia estaban relacionados y eran manifestaciones de desaprobación por el regreso de Calderón. Probablemente, fueron realizadas por el sector que había practicado el terrorismo durante la década de $1940,{ }^{59}$ generando un ambiente de inestabilidad que anunció la Guerra Civil.

No se hicieron esperar las condenas públicas al ametrallamiento a la casa de Calderón, desde diversos sectores y en distintos periódicos. Por ejemplo, Echandi declaró: «Estoy profundamente apenado de que un acto de esa naturaleza se haya cometido en este gobierno [...] El Gobierno está dispuesto a terminar con esos brotes de irresponsabilidad que crean desasosiego en el país». ${ }^{60}$ Por otra parte, en la Asamblea Legislativa, el diputado Orlando Sotela se pronunció a favor de realizar una condena, especialmente, por tratarse de un atentado contra un diputado, la cual se hizo efectiva el 15 de julio de 1958. Incluso, con motivo de la visita al país de varios miembros del Federal Bureau of Investigation de los Estados Unidos (FBI), se sugirió solicitarles su apoyo para esclarecer lo ocurrido. Efectivamente, luego se abrió un exediente ante los Tribunales Comunes,

56 La Nación, «El atentado contra el Dr. Calderón», 15 de julio de 1958, 6.

57 La Hora, «Ametrallada...», 14 de julio de 1958, 1 y 5.

58 La Nación, «Impactos de calibre 45», 15 de julio de 1958, 1 y 15.

59 Manuel Solís Avendaño, La institucionalidad ajena. Los años cuarenta y el fin de siglo (San José: EUCR, 2006), 290 y 296.

60 La Nación, «Condeno definitivamente el atentado», 15 de julio de 1958, 1-2. 
Calderón sostuvo en su declaración que se trataba de un hecho aislado y desvinculado de la política. ${ }^{61}$

Desde distintos sectores hubo temor de que este atentado pudiera desencadenar un nuevo período de violencia. Sobre este delito, Díaz concluye que «en lugar de pedir a sus partidarios que se unieran a la violencia, los diferentes partidos políticos unieron sus voces para pedir una investigación de hecho por parte de la policía y para llamar a la calma» ${ }^{62}$

En un Editorial del semanario Adelante el ataque fue interpretado como una acción de quienes tenían intereses en que se enfrentaran los calderonistas y los figueristas, quienes también querían crear un ambiente de inestabilidad que propiciara la persecución de comunistas, en vísperas de la llegada de Milton Eisenhower al país. Incluso, en esta publicación se plantea que Otilio Ulate es el culpable de los atentados simultáneos en Heredia. ${ }^{63}$ Así como había sucedido con los atentados ocurridos durante el período de La Junta, y los gobiernos de Ulate y de Figueres, se señaló a los comunistas como los autores, pero ellos aseguraban que era una estrategia para justificar su persecución.

Como se ha mostrado, en términos generales, a diez años de la Guerra Civil y con el inicio del gobierno de Echandi, se percibe un cambio a nivel discursivo desde los sectores «enemigos», principalmente desde el calderonismo. Para Díaz, «los discursos de violencia que fueron tan comunes en el período 1942-1958, de repente se volvieron extraños» ${ }^{64}$ Sin embargo, un pequeño sector se resiste a abandonar la violencia, pero queda cada vez más aislado e ilegitimado. Así, las diversas manifestaciones de violencia política que habían caracterizado al período de posguerra empezaron a concebirse como actos de irracionalidad y locura, y en contraposición, la conciliación nacional en sinónimo de razón y cordura.

\section{Rituales de inclusión}

Por rituales de inclusión, se entiende, todas las acciones realizadas durante el gobierno de Echandi con el propósito de reconocer, públicamente, que los derechos de los vencidos de la Guerra Civil de 1948 fueron violentados, producto de la característica persecución política de la posguerra costarricense. Así como el objetivo de restablecer su condición de sujetos políticos e implementar medidas de compensación. Dichas acciones pudieron ser de tipo legal o simbólico y permitieron la recuperación paulatina de derechos y de espacios. Además,

61 República de Costa Rica, Colección de Leyes y Decretos, II Semestre, 1958, 32; La Hora, «Intervención...», 21 de julio de 1958, 1 y La Nación, «Ratifica ante los Tribunales Comunes...», 18 de julio de $1958,5$.

62 Díaz Arias, Crisis social y memorias en lucha..., 321.

63 Adelante, «Quien dirigió el atentado...», 20 de julio de 1958, 2.

64 Díaz Arias, Crisis social y memorias en lucha..., 321. 
dichas medidas se llevaron a cabo en algunos casos por iniciativa del gobierno y en otros, de la sociedad civil. De esta forma, los rituales de inclusión son considerados parte de los rituales políticos de conciliación.

Una de las primeras acciones realizadas por el gobierno de facto de $\mathrm{La}$ Junta, fue la colocación del retrato de León Cortés en la oficina de Figueres en la Casa Presidencial, lo que puede interpretarse como una forma de legitimación, al representar una continuidad entre ambos caudillos, es decir, una especie de herencia. A su vez, el retrato de Calderón fue guardado. Este acto de sustitución de retratos era, asimismo, un acto simbólico de sutitución del poder. Teniendo esto presente, al iniciar el gobierno de Echandi, el diputado Rojas Tenorio de la provincia de Guanacaste, propuso colocar el retrato de Teodoro Picado en la galería de retratos de exmandatarios, explicando que sería un gesto de cordialidad y «no tenía matices políticos y menos tendía a romper la armonía y el buen propósito de esta cámara de alejarse de la política...»». ${ }^{65}$

La propuesta generó una serie de opiniones valiosas de recuperar como muestra de la reflexión que se gestaba en torno a la conciliación nacional. En primer lugar, Montero Padilla, presidente de Asamblea Legislativa, hizo «un llamamiento a la cordura y al sentimiento de confraternidad entre los costarricenses, que se verán robustecidos con estos gestos que significan que, si algunos errores pudo haber cometido el licenciado Picado en el ejercicio del poder, estos han quedado olvidados». Por su parte, el diputado Luis Alberto Monge señaló: «estamos frente a la patriótica necesidad de sanar heridas» y el diputado Hernán Garrón aseguró: «el país desea la paz y armonía entre los costarricenses y que desaparezcan los odios. Hay que superar esas pasiones y los del Liberación lo estamos haciendo, en servicio del país». Mientras que el diputado Fabio Fournier afirmó: «Lo he visto sufrir el calvario de su expatriación y de sus enfermedades y no puedo olvidar al brillante profesor y escritor para quien en todo momento he guardado el afecto y el respeto más profundos» ${ }^{66}$

Finalmente, se realizó una votación y la propuesta de colocar el retrato de Picado en la galería de expresidentes obtuvo cuarenta votos a favor y cuatro en contra. A pesar de ser un acto simbólico, a lo interno de la Asamblea Legislativa da cuenta de la forma en que estaban transformándose las relaciones políticas y en general, la memoria sobre la Guerra Civil de 1948. Los enemigos empezaban a coincidir en que la conciliación nacional era necesaria para restaurar el tejido social, de esta manera, la equiparación de las violencias ejercidas por ambos bandos era el camino que llevaría al olvido. Para que las elecciones fueran consideradas el único mecanismo de acceso al poder debía existir, primero, una renuncia a la violencia, aunque esto último slo podía ocurrir mediante el perdón oficial.

65 La Nación, «Brilla de nuevo en la Casa Presidencial...», 11 de mayo de 1948, 1.

66 La Nación, «Retrato del ex-Presidente Picado...», 7 de junio de 1958, 8. 


\title{
Recuperando derechos y espacios
}

Durante la posguerra costarricense, los perdedores de la Guerra Civil fueron excluidos de diversos espacios, como fue de la contienda político-electoral y se les limitó el acceso a los medios de comunicación. Por lo anterior, el cambio más evidente se dio en las elecciones de 1958. Después de diez años los calderonistas volvieron a ocupar diputaciones. No obstante, los comunistas continuaron excluidos de la lucha electoral hasta 1975. Ahora, con el inicio del gobierno de Echandi hubo una mayor tolerancia con respecto al acceso al ámbito público, a las calles, la prensa y la radio. Pues durante el período de La Junta, así como los gobiernos de Ulate y, posteriormente de Figueres hubo políticas de censura y violación a la libertad de expresión. Por ejemplo, en 1951 Mora denunciaba «Todas las puertas de la prensa nacional están cerradas para un sector de la ciudadanía al cual pertenezco yo...». ${ }^{67}$ Asimismo, en 1954 a Mora se le prohibió dar un discurso radial, por lo cual interpuso un Recurso de Amparo sin tener éxito. ${ }^{68}$ Esta situación de exclusión se vería claramente modificada en julio de 1958. Como se muestra en el siguiente discurso del diputado Sotela, propietario de la Radio Atenea, por petición expresa de Echandi, dicha estación radial le cedería el espacio a Mora para que diera un discurso, detallando lo siguiente:

\begin{abstract}
pese a la afirmación que personalmente hiciera el Lic. Echandi Jiménez de que él asume la responsabilidad de esta transmisión al solicitar el espacio, quiero relevar al señor Presidente la gentileza que tuvo al hacernos esas manifestaciones, y nosotros en la radioemisora, queremos endosarnos la responsabilidad que esto implica, por cuanto sin ser amigos ni enemigos del señor Mora Valverde [...] tiene derecho a ocupar esta misma tribuna que tantas veces ha levantado su voz para darle más fuertes raíces a la libertad de expresión y pensamiento. ${ }^{69}$
\end{abstract}

Esta petición de Echandi no es una muestra de particular simpatía por los comunistas, por el contrario, él era un acérrimo anticomunista, como lo muestra su participación en el acto inaugural del $1^{\circ}$ Congreso Regional Anticomunista Centroamericano realizado el 28 de enero de 1959 en San José. Este evento fue convocado por la Federación Anticomunista Centroamericana (FAC).$^{70}$ Por lo anterior, pareciera que Echandi no quiso violentar la libertad de expresión de ningún sector, así seestablece en la siguiente declaración:

Para que hable un ciudadano por la radio, no necesita permiso oficial [...] En esto de que los ciudadanos digan lo que piensan, es preferible que se excedan, que limitarles la libertad de dar a conocer sus pensamientos, buenos o malos, que al fin,

67 La Nación, «Descubierta una red terrorista...», 1 de abril de 1951, 30.

68 La República, «Pronunciamiento...», 20 de junio de 1954, 6.

69 La Nación, «Sin ser amigos ni enemigos...», 18 de julio de 1958, 2.

70 Adelante, «El Congreso dio a luz...», 1 de febrero de 1959, 1 y Adelante, «El Congreso anti-comunista...», 1 de febrero de 1959, 3 . 
son responsabilidad exclusiva de quienes los expongan [...] Sabe él que vivimos en un régimen de opinión pública, que no es el mismo, afortunadamente, que el de los regímenes que suele defender con calor... ${ }^{71}$

En este punto, cabe preguntarse por qué se le presta tanta importancia a que Mora emita un discurso en la radio, al punto de que Echandi se haga públicamente responsable por las implicaciones de este acto. El discurso radial de Mora significó una ruptura de la cotidianidad, es decir, no era frecuente la participación de los comunistas en la radio o al menos, era de conocimiento popular que en los gobiernos anteriores habían sufrido restricciones. Por lo anterior, se podría plantear que durante el gobierno de Echandi los comunistas recuperaron de forma plena el derecho a la libertad de expresión, pues el Ejecutivo podía, como en otros períodos lo había hecho, solicitar previamente el discurso de Mora, sin embargo no lo hizo.

Sobre la forma como Echandi fue visto por los comunistas, destaca una interesante resolución del Comité Nacional del PVP. En ella se hacía un análisis del gobierno de Echandi en los siguientes términos:

[...] puede caracterizarse como un gobierno de tendencia centrista $[\ldots]$ aunque mantiene a nuestro partido en la semilegalidad, no se afana en perseguirlo [...] El Gobierno del señor Echandi ha sido respetuoso de la libertad de prensa y sindical y no se ha querido prestar a las maniobras antidemocráticas que se han realizado a través de los llamados Congresos Anti-comunistas. ${ }^{72}$

Los vencidos también tuvieron limitado su acceso a los espacios públicos; se les prohibió realizar manifestaciones, marchas o discursos. Los vencedores monopolizaron el ámbito público y relegaron a sus enemigos al ámbito privado, el cual, además, era constantemente intervenido por la policía. En el gobierno de Echandi empezaba a modificarse esa situación, pero algunos sectores desaprobaron los cambios. Por ejemplo, en un Editorial del periódico La Hora, propiedad de Ulate, se acusaba al Ministro de Gobernación de haber permitido una manifestación de comunistas el 15 de setiembre de 1958, esto a pesar de que la actividad había sido oficialmente convocada por la Federación de Juntas Progresistas. Además, se decía que habían improvisado una tribuna a las puertas de la casa presidencial donde, al igual que Mora, Echandi había dado un discurso. Este acto público fue caracterizado de «alarmante debilidad» del gobierno. ${ }^{73}$ Para Echandi dicho permiso se había concedido "porque no se justifica que precisamente el día de la Independencia y la Libertad en Costa Rica, se coartara el derecho de desfilar a los ciudadanos [...] Sí me complació mucho que los costarricenses

71 La Nación, «Preferible que se excedan...», 21 de setiembre de 1958, 11.

72 Adelante, «V.P. enfoca situación política...», 22 de febrero de 1959, 4.

73 La Hora, «Exigimos...», 18 de setiembre de 1958, 3 y La República, «Echandi hablará a las juntas progresistas», 14 de setiembre de 1958, 17. 
llegaran hasta la Casa Presidencial, porque ellos tenían la certeza de que no los iba a recibir con tiros». ${ }^{74}$

Como parte de las actividades programadas el 15 de septiembre de 1958, en el Parque Morazán se inauguró el Monumento a los Héroes, también llamado Monumento al Soldado Desconocido, homenaje realizado por las escuelas y colegios de Costa Rica y dirigido por Estela Quesada ${ }^{75}$, Ministra de Educación, (Ver Imagen 2). En la prensa se señaló que dicho monumento era un «recuerdo de cuantos cayeron a través de los años en los distintos campos de batalla...». ${ }^{76}$ Este acto es parte de los rituales de inclusión, pues el anonimato se convierte en una conmemoración al costarricense, un homenaje cívico y no político que convocaba a todas las tendencias políticas.

\section{Imagen 2. Placa conmemorativa}

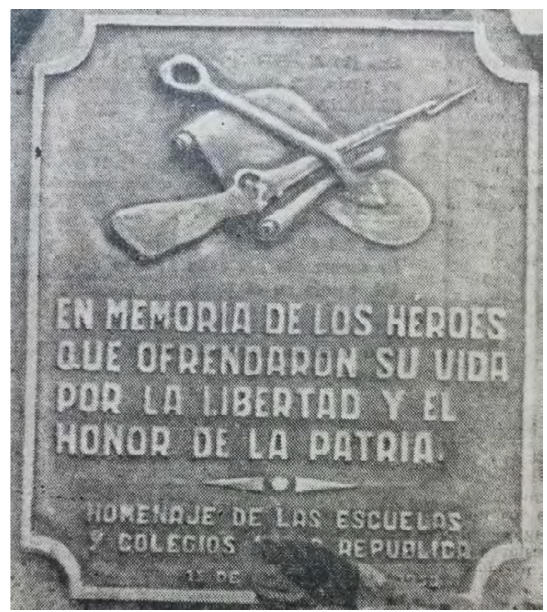

Fuente: La Nación, 17 de septiembre de 1958, 40.

Otra de las formas como fueron violentados los derechos de los vencidos, especialmente de los comunistas, fue mediante la intervención de su correspondencia y el frecuente decomiso de material considerado propaganda comunista. En octubre de 1958, la prensa informó sobre un caso donde se demostraba que esta situación continuaba durante el gobierno de Echandi, se trataba de un decomiso de material realizado a Nydia Sáenz Ruiz, el cual había llegado por mar después de que ella había viajado «tras la Cortina de Hierro», y supuestamente, sería utilizado para el adoctrinamiento de niños y jóvenes. ${ }^{77}$ Asimismo,

74 La Hora, «Totalmente falso...», 18 de setiembre de 1958, 3.

75 La República, "El Misterio de Educación Pública», 14 de setiembre de 1958, 20.

76 La Nación, «Bello desfile patriótico», 17 de setiembre de 1958, 40.

77 La Nación, «Propaganda roja», 17 de octubre de 1958, 26. 
en marzo de 1959, un comunicado dirigido a los Administradores de Aduanas les recordaba que, según el decreto N³7 de 1954, se prohibía la importación y circulación de todo material de ideología comunista, por lo que se ordenaba su desalmacenaje y ponerse en comunicación con el Ministro de Gobernación. Además, se mencionaba que, según un informe del Jefe del Servicio de Inteligencia, en los últimos meses, el Partido Comunista había tenido gran actividad introduciendo propaganda de la Unión Soviética, por lo que se habían realizado decomisos en el correo, el aeropuerto y las aduanas. ${ }^{78}$

A pesar de lo descrito anteriormente, en diciembre de 1959 se registra un cambio significativo. Arnoldo Ferreto, Antonio Acosta y Gladys Sáenz habían sufrido el decomiso de material traído luego de un viaje a China. Al respecto, el Ministro de Gobernación, le dirigió una carta al Director General de Detectives donde le indicó:

\begin{abstract}
He meditado muy detenidamente sobre el camino a tomar en este caso y sobre la interpretación que debe darse al Decreto Ejecutivo $\mathrm{N}^{\circ} 37$ de 21 de julio del año 54 , decidiéndome por lo que me parece saludable y conveniente para los intereses democráticos de la república: devolver a sus propietarios las pertenencias que les fueron decomisadas, tan pronto como se presenten a reclamarlas. ${ }^{79}$
\end{abstract}

La justificación del Ministro era que en cualquiera de las librerías del país se encontraban libros marxistas, por lo que no tenía sentido el decomiso. Es importante mencionar que Vargas Gené había sido de los periodistas heridos en un ataque aéreo en el territorio de la Casona de Santa Rosa, en la provincia de Guanacaste, mientras cubría la invasión de 1955 junto con su hermano Jorge Vargas Gené, ambos corresponsales de La Nación. Como consecuencia de las heridas, este último falleció. Por ende, el Ministro también había sido víctima de la violencia política de la posguerra sin estar directamente vinculado con ninguno de los bandos enfrentados. Sobre las declaraciones de Vargas Gené en el semanario Adelante se publicó el siguiente comentario:

El Gobierno de la República ha dado un paso más hacia la restitución de los derechos democráticos de nuestro pueblo. Primero restableció el derecho de reunión y de expresión para todos. Ahora ha restablecido el derecho de leer, que es parte fundamental del derecho de pensar [...] vuelve Costa Rica por los fueros de sus mejores tradiciones. ${ }^{80}$

La cita anterior es importante porque confirma cambios con respecto al acceso a derechos que habían sido restringidos antes del gobierno de Echandi.

78 ANCR, Ministerio de Gobernación (MG), 41484, s.f.

79 La Nación, «Devolver folletos...», 3 de diciembre de 1959, 27. En el ANCR se encuentra material decomisado con información sobre China, escrito en español, inglés y francés, ver: ANCR, Ministerio de Seguridad Pública (MSP), Dirección General de Detectives (DGDET), 889, f. 1-39.

80 Adelante, «Restablecida la libertad...», 6 de diciembre de 1959, 1. 
Hubo variantes como la libertad de expresión, de reunión, el acceso a medios de comunicación y la libertad de pensamiento. Además, estas permutas estaban favoreciendo principalmente a los comunistas, los más afectados por la persecución y represión ejercida por los vencedores. Sin embargo, no se hicieron esperar los reclamos hacia el Ministro de Gobernación, como fue el caso de Gabriela Stein de Guzmán, presidenta de la agrupación anticomunista llamada Acción Femenina Cristiana (AFC), quien le dirigió una carta en junio de 1961 cuestionando por qué en Costa Rica se permitía la publicación y libre circulación de propaganda comunista y periódicos como Adelante, El Sol y Sinjua ${ }^{81}$

Ahora, es necesario señalar que los mecanismos de control del Estado sobre los comunistas se reactivaron con motivo del triunfo de la Revolución Cubana en 1959, así como por la huelga por el aguinaldo en las zonas bananeras, por señalar un ejemplo, algunos detectives le prohibieron a Carlos Luis Fallas abordar un vuelo hacia Golfito en enero de 1960 su respuesta fue plantear un recurso de hábeas corpus. ${ }^{82}$ Además, en el gobierno de Francisco Orlich, la inspección y el decomiso de material considerado comunista retomaron fuerza

\section{Medidas de compensación}

El inicio del gobierno de Echandi abrió el debate sobre las arbitrariedades e injusticias cometidas producto de las sentencias emitidas por los Tribunales Especiales creados por el gobierno de facto de La Junta. Como identificó Claudia Quirós, el Tribunal de Sanciones Inmediatas (TSI) resolvió 922 casos de los cuales 322 personas fueron condenadas ${ }^{83}$ La crítica se concentró, particularmente, en el Tribunal de Probidad, encargado de investigar los casos de corrupción y enriquecimiento a expensas del Estado durante los gobiernos de Calderón y de Picado. Ante dicho tribunal, los mismos acusados debían demostrar que sus bienes habían sido adquiridos de forma honesta.

En julio de 1958, el diputado Guillermo Villalobos presentó un proyecto a la Asamblea Legislativa que buscaba la revisión de las sentencias del Tribunal de Probidad, alegando:

no es propio que perduren, dentro del actual régimen constitucional, los efectos de las sentencias condenatorias dictadas por un tribunal especial $[\ldots]$ que actuó

81 ANCR, fondo MG, 40315, fs. 5-10.

82 La Nación, «Líder comunista Carlos Luis Fallas...», 8 de enero de 1960, 8. Algunos ejemplos de decomisos de material considerado comunista durante el gobierno de Orlich son: la inspección del escritorio de Franklin Sánchez Torres, oficinista de la Aduana Principal, y de su casa, ver: ANCR, Ministerio de Economía y Comercio (MEIC), f. 2575, s.f. Decomiso de material a Roy Mena Chávez estudiante de la Universidad de Costa Rica que regresaba de Cuba, ver: ANCR, MG, f. 36406, f. 1. Decomiso de material comunista en Puerto Cortés, ver: ANCR, MG, f. 41795.

83 Jacobo Schifter, La fase oculta de la guerra civil en Costa Rica (San José, Costa Rica: Editorial Universidad Centroamérica, 1986), 113 y Claudia Quirós, Los tribunales de Probidad y de sanciones inmediatas (Centro Regional de Occidente, Coordinación de Investigación, UCR), 96-98 y 108. 
fuera de la órbita y el control del Poder Judicial, sin que las sentencias puedan ser revisadas por los tribunales ordinarios... ${ }^{84}$

Sin embargo, el proyecto de Villalobos no tuvo éxito. ${ }^{85}$ Se podría afirmar que si bien, los Tribunales Especiales ya no funcionaban de forma oficial, continuaban operando mediante sus sentencias y sus consecuencias. De ahí, la necesidad de establecer revisiones a las sentencias e impulsar medidas de compensación a los afectados. Para ejemplificar lo planteado, el 20 de enero de 1959, el Ministro de Economía y Hacienda le envió un comunicado al Procurador General de la República en donde le informaba sobre una sentencia del 10 de marzo de 1958 del Tribunal de Probidad contra Marco Aurelio Castro Odio, En esta condenase establecía que Castro Odio le adeudaba 16.500 colones al Estado. Además de 5.940 colones de intereses atrasados y 1.022 colones de honorarios, los cuales debían de ser cancelados en el transcurso de un año después de la sentencia. ${ }^{86}$ Es decir, una década después de la Guerra Civil, la institucionalidad estatal se aseguraba de que las sentencias de los Tribunales Especiales fueran cumplidas.

También, existe evidencia de que el Tribunal de Probidad podía fallar a favor de los intervenidos y aún así estos perder sus bienes. Por ejemplo, el 1 de agosto de 1959, María del Rosario Fournier de Calderón solicitó, por medio de un apoderado judicial, pues se encontraba aún en México, el pago por los bienes y enseres domésticos que le fueron intervenidos — se adjuntaban las facturasAsegurándose de que, a pesar de la sentencia del 23 de agosto de 1949, donde el Tribunal de Probidad la favorecía bajo el argumento de que había contraído matrimonio con Calderón cuando este ya no era presidente; aún no había sido indemnizada por los bienes intervenidos. La petición de Fournier tuvo éxito hasta diez años después de la intervención. ${ }^{87}$

Otra iniciativa que también estuvo orientada a «corregir» lo que era considerado una injusticia, producto de las rencillas políticas de la Guerra Civil de 1948 fue la moción presentada por el diputado Enrique Fonseca Zúñiga cuyo fin era obtener un aumento de las pensiones de «varios centenares» de maestros que le habían escrito solicitando su intercesión en la Asamblea Legislativa. La situación era descrita de la siguiente forma: «en el año 1948 fueron expulsados de sus puestos, por represalias políticas y obligados muchos de ellos, ante la despiadada persecución, a pensionarse a como fuera lugar. Les adjudicaron pensiones bajísimas, siempre con el mismo ánimo de represalia»». ${ }^{88}$ De esta

84 La Gaceta, «Proyecto revisión de sentencias», 17 de julio de 1958, 1.

85 La Nación, «Revisión de las sentencias», 15 de julio de 1958, 1 y 12.

86 ANCR, fondo MEIC, 2166, fs. 5-32.

87 República de Costa Rica, Colección de Leyes y Decretos, II Semestre, 1959, 69-70.

88 La Nación, «Corregir injusticias...», 26 de agosto de 1958, 18. 
manera, se buscaba compensar a las personas afectadas mediante la revisión de los montos de sus pensiones.

El 7 de noviembre de 1959, la Asamblea Legislativa aprobó una propuesta presentada por el diputado Morera Soto para la revisión de sentencias del Tribunal de Probidad. Su objetivo era que quienes habían sido condenados o no pudieran defenderse por estar fuera del país y tuvieran un plazo de 2 años para solicitar un recurso de revisión, el cual también podía ser interpuesto por herederos o un albacea. Además, en caso de dictarse una sentencia favorable al intervenido, el Poder Ejecutivo debía restituir los bienes adquiridos por el Estado y en caso de que hubieran sido rematados o traspasados a terceros, se le daría el valor de los bienes al intervenido. ${ }^{89}$

Amparado en esta nueva legislación, el 19 de abril de 1960, Calderón solicitó la revisión de su sentencia y finalmente, el 4 de abril de 1962, el gobierno acordó restituirle una propiedad que consistía en tres fincas, todas ocupadas por el Liceo de Señoritas Anastasio Alfaro. ${ }^{90}$ De esta forma, durante el gobierno de Echandi se estableció la posibilidad de solicitar la revisión de las sentencias del Tribunal de Probidad, reconociéndose que dicha institución había sido creada por los vencedores, al calor de la guerra.

\section{Armas por tractores}

Dentro de las políticas dirigidas por el gobierno de Echandi se planteó el desmantelamiento de los arsenales nacionales, mediante la venta o intercambio de armas consideradas innecesarias, especialmente, a diez años de la proscripción del ejército. Desde la campaña electoral, el PUN había anunciado que «eliminaría el ejército», las armas serían vendidas y se invertiría en mejorar las condiciones de los maestros y las escuelas. ${ }^{91}$ Fue así, como al iniciar el gobierno de Echandi, se anunció el interés de recoger todas las armas que en poder de particulares. Como señaló la prensa, esto ocurría porque «con motivo de las revoluciones e invasiones al territorio, que se efectuaron desde el año 48, el gobierno anterior se vio en la necesidad de armar a particulares, quienes formaron el cuerpo llamado de reservistas»». ${ }^{92}$

Por cuenta propia, como consta en la prensa, algunas personas decidieron realizar la devolución de armas, principalmente, de rifles. Por ejemplo, en

89 La Nación, «Revisión de sentencias...», 13 de noviembre de 1959, 19; República de Costa Rica, Colección de Leyes y Decretos, II Semestre 1962, 383-385. También se encontró el caso de la petición de Etelvina Picado Ramírez quien como albacea de Teodoro Picado, solicitó el 1 de marzo de 1961 (estando en Nicaragua) la restitución del derecho telefónico, en: Colección de Leyes y Decretos, I Semestre 1962, 276-277.

90 República de Costa Rica, Colección de Leyes y Decretos, II Semestre, 1959, 69.

91 La Nación, «Gastando los millones en ejércitos», 1 de setiembre de 1957, 12. Esta política que podría calificarse de desmilitarización es de las más recordadas del período de Echandi, como se observa en la página oficial de la Asamblea Legislativa de Costa Rica: http://www.asamblea.go.cr/ca/Expresindentes\%20 de\%20Costa\%20Rica/Forms/DispForm.aspx?ID=30.

92 La Hora, «Requisa de armas...», 3 de junio de 1958, 1. 
Ciudad Quesada, el Mayor Campos López comunicó que once ex-reservistas se habían acercado a su despacho a devolver, voluntariamente, armamentos que tenían en su poder. Específicamente, once fusiles M-1 y equipo de guerra: cascos, mochilas, fatigas, parque, entre otras cosas. Luego, se anunció la devolución, en Grecia, de rifles M-1 y Máuser a la Secretaría de la Comandancia en Jefe, armas conservadas por reservistas desde la invasión de $1955 .{ }^{93}$ A pesar de estas iniciativas, pareciera que la respuesta no fue la esperada por el gobierno, pues se informó:

[...] se procederá drásticamente contra elementos que con fines inconfesables retienen, armas hasta de grueso calibre, que no tienen por qué estar fuera de los arsenales del Estado [... . como se ha informado, el Gobierno ha pedido a los reservistas que reintegren esas armas a los arsenales pero en muy contados casos se ha conseguido ese resultado. ${ }^{94}$

Un año después, se notificó que el Ministro de Gobernación, con instrucción del presidente, había redactado un proyecto de ley cuyo objetivo era intercambiar las armas en desuso de los ministerios de Gobernación y de Seguridad Pública por implementos agrícolas e industriales, los cuales,a su vez, serían entregados al Ministerio de Agricultura y al Ministerio de Justicia. Además, se planteó la posibilidad, de incluir en la propuesta, la venta de los dos aviones de combate adquiridos por el gobierno con motivo de la invasión de $1955 .{ }^{95}$

En esa ocasión, se mencionó que el intercambio se realizaría con la International Armament Corporation de los Estados Unidos, pero durante la transacción apareció otro interesado, W. Gough, representante de la firma Hy Hunter American Weapons Corp. quien se dirigió al Ministro de Gobernación ofreciendo un monto más alto que la International Armament Corporation. Finalmente, la Asamblea Legislativa autorizó al Poder Ejecutivo a realizar la transacción con la primera empresa. ${ }^{96} \mathrm{El}$ tipo de armamentos y municiones, así como se describen, en la siguiente tabla, las cantidades entregadas por el gobierno (Ver Tabla 1)

Tabla 1. Material Entregado a la International Armament Corporation

\begin{tabular}{|l|r|}
\hline Tipo & Cantidad \\
\hline $\begin{array}{l}\text { Fusiles Mauser (cañón largo 1028, cañón corto 653, } \\
\text { argentinos 70, sin identificar 50) }\end{array}$ & 1801 \\
\hline Fusiles Remington & 599 \\
\hline
\end{tabular}

93 La Nación, «Devuelven Reservistas...», 6 de julio de 1958, 58; La Hora, «Armamento fue entregado...», 23 de agosto de 1958, 1 y 8.

94 La Hora, «Acción judicial contra reservistas...», 14 de agosto de 1958, 8.

95 La Nación, «Ley de cambio de armas...», 13 de noviembre de 1959, 3.

96 República de Costa Rica, Colección de Leyes y Decretos, II Semestre, 1959, 513. 


\begin{tabular}{|l|r|}
\hline Fusiles automáticos (Breda 230 y Reising 134) & 364 \\
\hline Fusiles ametralladoras (Johnson 117 y Degtyarov 14) & 131 \\
\hline Carabinas (Oviedo 110, U.S. Kragg 40, Mauser 55) & 205 \\
\hline Fusiles de varias marcas en mal estado & 64 \\
\hline Ametralladoras (Breda 26, Reising 23, Maxim 15) & 42 \\
\hline $\begin{array}{l}\text { Subametralladoras (Reising 22, Beretta 14, Smeiser 3 y } \\
\text { Neauhasen 3) }\end{array}$ & 38 \\
\hline $\begin{array}{l}\text { Fusiles (Norteamericanos M-1 23, Moisin 7, Savage 5, } \\
\text { japoneses 2, chispa 1) }\end{array}$ & 6 \\
\hline Ametralladoras (Colt 4 y Gatling 3) & 4 \\
\hline Pistolas Tru-Flite (para señales) & 584 \\
\hline Cañones Hotchkiss (marina 2 y terrestre 2) & 1085401 \\
\hline Repuestos: cañones para fusiles (varias marcas) & 64 \\
\hline Municiones: tiros (varias marcas) &
\end{tabular}

Fuente: Elaboración propia a partir de la Colección de Leyes y Decretos, 1959.

Este intercambio, propició el surgimiento de discursos originarios de la representación de Costa Rica como un país pacifista, donde se prefería invertir en economía en vez de armas. En este sentido, Echandi se dirigió a la población costarricense con las siguientes palabras:

Vamos a dar cañones y ametralladoras que matan por instrumentos que dan vida, que hacen más prósperos y más felices a los hombres. Eso se puede hacer porque los costarricenses han demostrado que pueden convivir entre ellos y con los otros pueblos en paz, en armonía, cultamente, como corresponde a los habitantes de un país civilizado que ama sobre todas las cosas su civilidad. ${ }^{97}$

Por su parte, los comunistas costarricenses, que estaban a favor del desarme no solo de Costa Rica, sino mundial, señalaron en el semanario Adelante que:

Cumpliendo una promesa hecha al pueblo durante la campaña electoral pasada, el Presidente Echandi ha obtenido licencia de la Asamblea Legislativa para vender una cierta cantidad de armas y comprar a cambio máquinas agrícolas [...] Nosotros estamos, sin reservas en contra de la carrera armamentista y en favor del desarme tanto en escala nacional, como regional y mundial. ${ }^{98}$

97 La Nación, «Ametralladoras y cañones...», 2 de diciembre de 1959, 7.

98 Adelante, «Al desarmarse Costa Rica...», 6 de diciembre de 1959, 1. 
En la misma línea, un grupo de mujeres organizadas de la provincia de Puntarenas aprovechó el anuncio del intercambio de armas por tractores y la proximidad de la Navidad, para dirigirse a la primera dama, Olga de Echandi, solicitándole:

[...] su voz de apoyo, como primera dama de la República al Gran Plan de Desarme Mundial que se está discutiendo en la sede de las Naciones Unidas [...] las mujeres costarricenses, como lo están haciendo millones de mujeres de todo el mundo, debemos manifestar nuestra opinión al discutirse el más trascendental de todos los problemas políticos que afronta la Humanidad en estos momentos: el problema de la Paz...99

En una ceremonia, en la Tercera Compañía de la Guardia Civil, se hizo entrega de los armamentos recolectados por el gobierno de Costa Rica a la compañía norteamericana. Las armas habían sido avaluadas por el coronel Holden, militar de la Embajada de los Estados Unidos. A cambio, el gobierno recibiría seis tractores marca Fordson; seis arados, marca Ramsomes y seis rastras, de la misma marca, todos nuevos. Además de una cepilladora de madera mecánica. Como acto simbólico, Echandi entregó una ametralladora en manos del embajador estadounidense Willawer. Este último, dio las siguientes declaraciones: «Recibo esta ametralladora como símbolo de paz, porque las armas de que se deshace el gobierno de Costa Rica irán a un país que sólo emplea las armas para cuidar la paz y éstas, van a ser adorno de un museo». Asimismo, Echandi recordó que este intercambio era el cumplimiento de una de sus promesas de campaña electoral y tenía como propósito satisfacer «la aspiración de vivir siempre en la civilidad, la de encontrar su fortaleza en la fuerza de sus instituciones, la de sentir que sus armas son el libro y la pluma». ${ }^{100}$

Sin duda, esta medida del gobierno de Echandi también contribuía a fortalecer la idea, ampliamente difundida, de que el ejército de Costa Rica son sus maestros y estudiantes. Para Alfonso González, este intercambio de armas por tractores tuvo un profundo significado político y cultural, pues representaba crecimiento y madurez, en el sentido de que se entregaban armas «símbolo de la inmadurez» y se recibía maquinaria, herramientas de trabajo. Así, este ritual político desarrollado en el escenario de las relaciones internacionales, es interpretado por González, como un rito de paso entre la infancia y la adultez política, como colectividad y como individuos. ${ }^{101}$

99 Adelante, «Las mujeres de Puntarenas...», 6 de diciembre de 1959, 5; Nuestra Voz, «Carta a la primera dama...», junio de 1959, 1-2 y Nuestra Voz, «Comisión de Mujeres...», julio de 1959, 3.

100 República de Costa Rica, Colección de Leyes y Decretos, II Semestre, 1959, 515 y La Nación, «Cambio de armas...», 28 de diciembre de 1959, 8.

101 Alfonso González. Mujeres y hombres de la posguerra 1950-1960 (San José: Editorial de la Universidad de Costa Rica. 2005), 30-31. 
Por último, es importante mencionar dos ejemplos de otras iniciativas, orientadas a debilitar el militarismo en Costa Rica. El primero, la adscripción del departamento de bandas al Ministerio de Educación Pública, con lo cual se eliminaba el carácter de cuerpos militares que habían tenido y se proponía darles la condición de orquestas filarmónicas. ${ }^{102} \mathrm{El}$ segundo, se identificó en un artículo de prensa titulado «Desaparece otro cuartel», donde se informó que el Poder Ejecutivo había tomado la decisión de utilizar las instalaciones del cuartel de Alajuela para la fundación de un colegio vocacional. ${ }^{103}$ De esta forma, los elementos militares eran progresivamente sustituidos por elementos representantes dela educación, el trabajo y la paz.

\section{Nicaragua como amenaza a la democracia costarricense}

En artículo propone que la conciliación nacional fue un proceso favorecido por elementos internos, como la llegada de Echandi a la presidencia que significó el final del gobierno de los vencedores. Y también, por factores externos que involucraron a Nicaragua, pues debido a la intensificación del enfrentamiento a la dictadura somocista, se generó una gran actividad por parte de las fuerzas revolucionarias en la zona norte de Costa Rica, lo cual propició el surgimiento de nuevas representaciones en torno al «enemigo».

En este período, se fortalecen en Costa Rica las representaciones de país pacífico y democrático en contraste con su vecino del norte. Primero, se debe señalar que el mismo mes cuando Echandi llegó al Ejecutivo, la Asamblea Legislativa realizó una condenatoria contra los regímenes dictatoriales de todo el mundo, siendo el más cercano, el de Nicaragua. ${ }^{104}$ Por otra parte, en julio de 1958, la dictadura somocista, por medio del periódico nicaragüense Novedades, denunció por primera vez durante el gobierno de Echandi, la organización de un movimiento militar opositor en el territorio costarricense. ${ }^{105}$ A partir de este momento, las denuncias de ambos países serán frecuentes, así como la actividad de fuerzas armadas en la zona fronteriza del norte de Costa Rica.

Paulatinamente, se empezó a reconfigurar la relación amigo-enemigo, pero esta vez los enemigos ya no serán los vencidos de la Guerra Civil de 1948, sino un enemigo externo, extranjero, que hace uso del territorio nacional y que pone en peligro la estabilidad política de Costa Rica. Por lo anterior, no es de extrañar que la Asamblea Legislativa aprobara en septiembre de 1958, el Protocolo de la Convención sobre Deberes y Derechos de los Estados en caso de Luchas Civiles, el cual ya había sido suscrito en 1957. Este protocolo establecía en su Artículo 1 el compromiso de cada Estado por vigilar el tráfico de armas

102 La Nación, «Bandas militares», 25 de abril de 1959, 18. 
y de material de guerra que se presumiera estaba destinado a iniciar, promover o ayudar una lucha civil en otro Estado americano. Además, en el artículo 5 se aseguraba que cada Estado debía emplear todos los medios adecuados para evitar que cualquier persona, nacional o extranjera participara deliberadamente en la preparación, organización o ejecución de una empresa militar cuyos fines fueran iniciar, promover o ayudar una lucha civil en otro Estado contratante. ${ }^{106}$

En junio de 1959, la Asamblea Legislativa se dividió con respecto a la opinión sobre las fuerzas opositoras al gobierno de Luis Somoza que se encontraban en la zona norte. Un sector se declaró abiertamente a favor de la oposición nicaragüense, por ejemplo, José Rafael Cordero Croceri presentó una moción para apoyar al movimiento revolucionario de Nicaragua, exponiendo que se trataba de una lucha contra una dictadura y que además la Guardia Nacional nicaragüense estaba realizando violaciones al territorio costarricense. Por lo que declaró que tanto él como Frank Marshall y Marcial Aguiluz estaban dispuestos:

[...] a que si nos dan 20 hombres y nos situamos en puntos cercanos a la frontera, en ocho días le traemos al señor Echandi algún Guardia Nacional con todo y sombrero [...] Ante la manifiesta incapacidad del gobierno para hacer respetar el territorio costarricense, es que le ofrecemos nuestro concurso, para que nos permita defenderlo a nosotros. ${ }^{107}$

Finalmente, la Asamblea Legislativa aprobó la moción de dar un voto de simpatía y apoyo moral al movimiento revolucionario nicaragüense, con un total de 43 votos a favor y 2 en contra. A su vez, en las afueras de la embajada de Nicaragua se realizaron manifestaciones de apoyo que terminaron en ataques a la infraestructura. ${ }^{108}$ Por su parte, Echandi veía con recelo el apoyo de esta fracción de la Asamblea Legislativa a los nicaragüenses conspiradores, principalmente, por el conflicto internacional que podría generarle a su gobierno. Por lo que los acusó de tener:

[...] interés en crear dificultades al gobierno nacional [...] Cuando hablan en nombre del pueblo lo hacen cerrando los oídos a las voces de miles de madres, hermanas y novias costarricenses, quienes, sin tomar en cuenta el lado de que puedan estar sus simpatías en el conflicto nicaragüense, no quieren de ninguna manera que sus hijos, sus hermanos o sus novios tengan que arriesgar la vida... ${ }^{109}$

Para Echandi, quienes eran representados por Cordero Croceri, en el fondo querían traerle incertidumbre y sufrimiento a Costa Rica, como en los días de la Guerra Civil de 1948 y de la posterior violencia política de la posguerra. Por lo

106 República de Costa Rica, Colección de Leyes y Decretos, II Semestre, 1958, 168-170.

107 La Nación, «Apoyo moral a la revolución en Nicaragua», 3 de junio de 1959, 4-5.

108 La Nación, «Apedreadas...», 4 de junio de 1959, 4.

109 La Nación, «Crear dificultades al gobierno...», 8 de junio de 1959, 11 y La Nación, «En defensa de nuestra paz», 9 de junio de 1959, 12. 
que insistió en la supuesta tradición de neutralidad de Costa Rica, con el propósito de defender la política de no intervención. Como respuesta, un grupo de 500 estudiantes universitarios encabezado por Miguel Ángel Rodríguez se pronunció en contra de las dictaduras y en apoyo a la política de no intervención de Echandi, asegurando que el presidente actuaba «evitándole al país más muertos, más sangre, más lutos...». ${ }^{110}$

Posteriormente, se descubrió en un lugar llamado Punta Llorona, cercano a Corcovado, en la zona sur del país, un arsenal que presuntamente sería utilizado contra Somoza. Dentro de los involucrados se identificó a los diputados Marshall y Aguiluz, los nicaragüenses Salvador Castillo Solórzano y Mario Alfaro Alvarado y el dominicano Manuel Pichardo Fernández. ${ }^{11}$ Sin duda, este incidente preocupó al gobierno, pues se trataba de costarricenses junto a extranjeros fuertemente armados, a lo cual Aguiluz declaró:

[...] el señor Marshall y yo en este caso hemos actuado con plena responsabilidad, en cuanto a no ocultar que estamos contra la dictadura de los Somoza. Pero tanto él como yo no moveríamos un dedo contra las autoridades nuestras [...] La lucha es contra los sicarios de Nicaragua, no contra las autoridades de Costa Rica... ${ }^{112}$

Este incidente generó el establecimiento de una comisión mediadora dirigida por Rubén Odio, Arzobispo de Costa Rica. Mientras que Echandi aseguró no perseguir a nadie en su gobierno. Finalmente, se realizó el decomiso del arsenal almacenado en Punta Llorona y Echandi manifestó su satisfacción porque la negociación se dio en términos pacíficos:

[...] haberlo logrado, por fortuna para todos los costarricenses, por la vía pacífica de una generosa mediación y sin que se produjera una sola víctima ni un solo acto de violencia. Hemos impedido que esas armas se usen violando la neutralidad que el país está obligado a mantener y no hay un solo costarricense detenido, lastimado ni perseguido...113

Sobre la representación de Costa Rica como un país con una tradición de pacifismo y neutralidad, se puede observar en la siguiente caricatura de Seringa -Ver imagen 3-, la cual se titula «Cada uno en su casa y Dios en la de todos» e ilustra la conversación entre un representante de la Organización de Estados Americanos (OEA) y un campesino costarricense sobre lo ocurrido en Punta Llorona. Destaca la descripción sobre la forma como se solucionó el incidente,

110 La Nación, «Muestra pública de simpatía...», 18 de junio de 1959, 8.

111 La Nación, «Un enorme arsenal...», 20 de junio de 1959, 1 y 22; La Nación, «Terminó la aventura...», 24 de junio de 1959, 4. También se realizó un decomiso de armas en la finca Lindora, en Santa Ana, propiedad de Marcial Aguiluz, donde había una pista de aterrizaje y una avioneta, ver: La Nación, «Informe de las autoridades que practicaron...», 21 de junio de 1959, 62 .

112 La Nación, «Un enorme arsenal...», 20 de junio de 1959, 25.

113 La Nación, «El gobierno no persigue...», 20 de junio de 1959, 24-25. 
la llamada «vía costarricense» para la solución de conflictos. Además, se asegura que quienes no son «ciento por ciento» costarricenses son los que fallan, los que no se apegan a la «vía costarricense». Es decir, los violentos son los extranjeros, particularmente, los nicaragüenses. De esta forma, Nicaragua se empieza a configurar como el enemigo externo que pone en peligro la paz y la democracia de Costa Rica, sustituyendo a los enemigos internos, lo cual a su vez promueve la conciliación entre los costarricenses.

Imagen 3. «Cada uno en su casa y dios en la de todos»

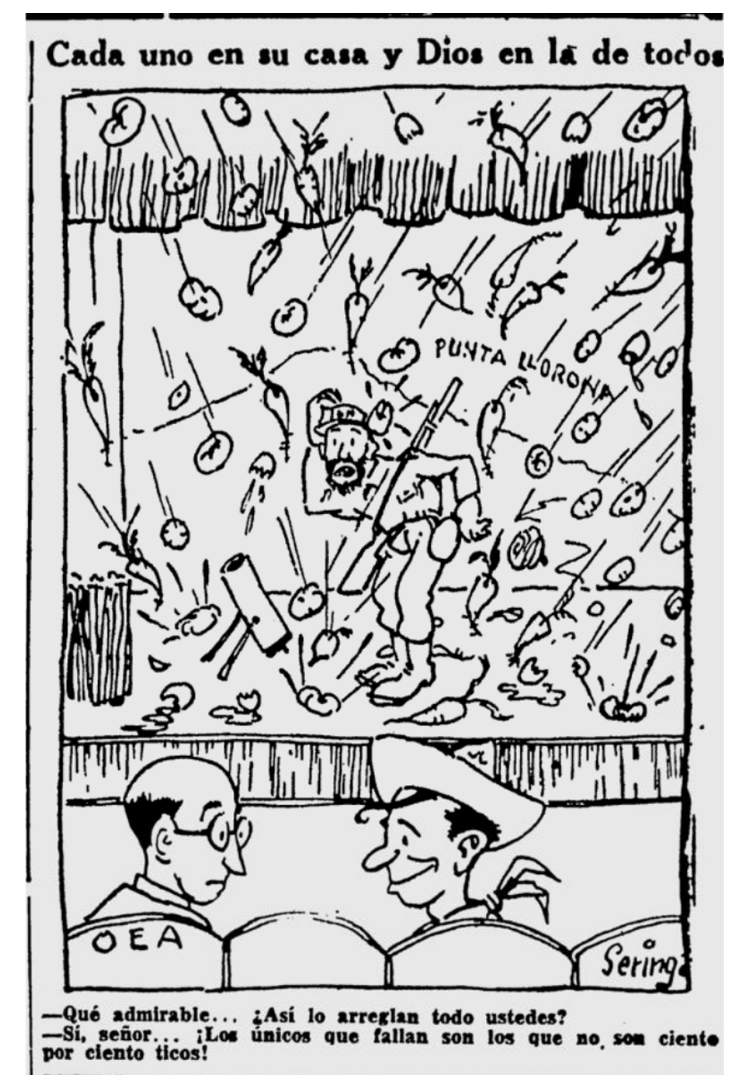

Fuente: La Nación, 21 de junio de 1959, p. 8.

Nicaragua se configura como un problema para Costa Rica. En un artículo de opinión, el Dr. Francisco Vargas Vargas afirmaba: «No pueden imaginar los honorables miembros de la OEA cuán difícil es, para un pueblo de paz 
-ampliamente demostrado con el hecho de no tener ejército- convivir a la par de una tiranía como la que ejercen los hermanos Somoza en Nicaragua...». ${ }^{114}$ Finalmente, Echandi consideró que su gobierno lejos de investigar el apoyo recibido por la oposición nicaragüense en Costa Rica, en realidad debía dar el tema por finalizado. Este argumento coincide con la idea de que la paz solamente se puede alcanzar por el esfuerzo de todas las personas. La renuncia de Echandi a hacer un análisis de los hechos ocurridos se fundamenta de la siguiente manera:

[...] la historia los recogerá y los analizará sin la pasión del momento [...] Hacerlo ahora, lo considero inoportuno y contrario al deseo del gobernante de dar por definitivamente terminada una situación anormal; sería contribuir, aunque fuera con la verdad, a dejar abierta una herida que me propongo restañar en procura del más patriótico y mejor interés nacional [...] A Dios debemos dar gracias por la feliz solución de nuestros problemas... ${ }^{115}$

Ignorar y olvidar el incidente de Punta Llorona fue la solución de Echandi. Sin embargo, no era garantía de que desaparecieran los grupos armados que se estaban organizando en Costa Rica para enfrentar al gobierno de Nicaragua. Al mes siguiente, de nuevo en la prensa se informó sobre rumores de un movimiento armado en Sarapiquí integrado por exiliados nicaragüenses. Esta vez, la respuesta del gobierno fue enviar guardias civiles para controlar toda la región del norte, de Peñas Blancas a Barra del Colorado, esta acción fue denominada «operación limpieza». ${ }^{116}$ Luego, el Consejo de Gobierno emitió un comunicado donde confirmó la presencia de un grupo de aproximadamente un centenar de insurgentes, descritos como en su mayoría extranjeros. Se aseguró que su intención era invadir Nicaragua, con lo cual podrían provocar un conflicto armado entre ambos países. No se niega la participación de costarricenses en dicha aventura, pero son representados como idealistas manipulados y utilizados por los líderes nicaragüenses:

Esas actividades están dirigidas por conocidos ciudadanos nicaragüenses que residen cómodamente en San José y que, si bien son capaces de enviar a la muerte a jóvenes idealistas, no lo son de tomar el mismo riesgo ni de respetar en lo mínimo la soberanía de la Nación y la vida de nuestros conciudadanos [...] estos individuos constituyen ya una amenaza para la paz y la tranquilidad de los costarricenses [...] Se trata de una amenaza a la paz de la República y de que se quiere conducir a la Nación a una tragedia... ${ }^{117}$

114 La Nación, «La OEA desconoce...», 20 de junio de 1959, 4.

115 La Nación, «Primero Costa Rica...», 26 de junio de 1959, 4.

116 La Nación, «Concentración de exiliados...», 28 de julio de 1959, 29; La Nación, «Para garantizar neutralidad...», 1 de agosto de 1959, 7 .

117 La Nación, «Consejo de Gobierno...», 9 de agosto de 1959, 8. 
El discurso predominante dice que los extranjeros estaban comprometiendo las normas de convivencia pacífica internacional, convirtiéndose en una amenaza para Costa Rica. Mientras, los costarricenses son eximidos de toda responsabilidad y son representados como personas influenciables. El discurso pacifista asumido por Echandi tuvo un giro luego de conocerse sobre un tiroteo contra una guarnición costarricense. Quien anteriormente había optado por olvidar los movimientos armados, ahora pronunciaba: «se procederá con mano fuerte contra quienes aparezcan como instigadores o responsables directos de la sangre costarricense que llegue a derramarse en la frontera Norte». ${ }^{118} \mathrm{La}$ advertencia se justificaba por la violación territorial y a la soberanía costarricense.

Como líder del grupo revolucionario se señaló al nicaragüense Indalecio Pastora, exiliado en Costa Rica. Al parecer, este grupo había cruzado la frontera ingresando al lado nicaragüense para instigar a la Guardia Nacional y luego se replegó al territorio costarricense. Como respuesta, la Guardia Nacional los había perseguido hasta la Hacienda San Paco, donde aparentemente quemaron la casa de Joaquín Leal, tomando presa a dicha familia y a dos guardas fiscales, ambos llevados a Nicaragua. ${ }^{119}$ Ante este incidente, la Asamblea Legislativa se cohesionó en apoyo a Echandi. Una comisión de diez diputados, dos de cada partido político, presentó una moción de apoyo franco y decidido al Poder Ejecutivo con motivo de la violación al territorio nacional por fuerzas armadas de la República de Nicaragua, por el irrespeto a las autoridades costarricenses y a los habitantes del territorio nacional, la cual fue aprobada. De esta manera, el nacionalismo empezó a actuar como elemento unificador ante la amenaza extranjera.

Incluso, algunos diputados que abiertamente habían apoyado a la oposición nicaragüense aprovecharon para manifestar su apoyo al gobierno de Echandi. Por ejemplo, Cordero Croceri señaló: «Debemos enfocar las cosas como costarricenses y no como partidos políticos...», y Marshall dijo: «Me pongo incondicionalmente a la orden del gobierno constitucional»» ${ }^{120}$ En un Editorial de $L a$ Nación se describió que los diputados, ante la violación al territorio nacional, habían actuado:

Como un solo hombre, dando una demostración de que por encima de nuestras rencillas internas hay algo sagrado que a todos nos hermana, los señores representantes de todos los grupos políticos de la Asamblea se pusieron a la disposición del Gobierno Constitucional de la República, para respaldarlo en su actitud defensiva

118 La Nación, «Frontera Norte», 13 de noviembre de 1959, 15.

119 Alfonso González establece que los grupos rebeldes se preparaban en las zonas fronterizas, desde donde incursionaban en territorio nicaragüense, atacaban y luego se replegaban a suelo costarricense, ver: González, «Mujeres y hombres de la posguerra...», 4 y La Nación, «Informa la comisión...», 18 de noviembre de $1959,11$.

120 La Nación, «Términos en que el gobierno...», 15 de noviembre de 1959, 17; La Nación, «Nota de protesta...», 16 de noviembre de 1959, s. p. y República de Costa Rica, Colección de Leyes y Decretos, II Semestre, 1959, 477. 
de la dignidad nacional atropellada. Actuaron, a nuestro entender, como verdaderos padres de la patria... ${ }^{121}$

A su vez, se presentó una protesta al gobierno de Nicaragua demandándole amplias explicaciones sobre los hechos cometidos por miembros de la Guardia Nacional, sugiriéndose, además, la destitución de todos los miembros de la Guardia Nacional involucrados en el ataque a la guarnición costarricense. El gobierno de Costa Rica declaró «zona militar» el área comprendida en una faja de 25 kilómetros de ancho a lo largo de toda la frontera del país. ${ }^{122}$ Sin embargo, estas medidas no frenaron las amenazas, pues en febrero de 1960, de nuevo, la prensa informó sobre enfrentamientos entre la Guardia Civil y rebeldes ubicados en Costa Rica, describiéndose, incluso, la presencia de ametrallamientos desde el aire. ${ }^{123}$

También, empezaron a aparecer discursos que representaban a los nicaragüenses exiliados en Costa Rica como traidores, pues estaban traicionando los beneficios que el gobierno de Echandi les había otorgado con el asilo político, ya que sus actividades ponían en peligro la tranquilidad del país que los había acogido. En un telegrama oficial, Echandi se dirigió al Jefe del Movimiento Opositor Nicaragüense, el Dr. Enrique Lacayo Farfán, quien se encontraba exiliado en Costa Rica, solicitándole:

Yo apelo a su caballerosidad para que, con los conductos que usted conoce, haga usted al señor Indalecio Pastora deponer las armas y salir de nuestro país, en beneficio y tranquilidad del pueblo que tan amplia y noble acogida le ha dado a todos los que a sus puertas tocan [...] estoy seguro de que usted no puede compartir con el señor Pastora la responsabilidad inmensa de estar haciendo fuego contra la Guardia Civil... ${ }^{124}$

Echandi le ofreció a Lacayo Farfán todas las facilidades para desplazarse a la frontera norte donde estaban operando los rebeldes con el propósito de que se pusiera en comunicación con Pastora. En este punto, el gobierno de Costa Rica tenía solamente dos opciones. La primera, enfrentar a las fuerzas de Pastora para controlar sus actividades y así evitar provocaciones a la Guardia Nacional nicaragüense. La segunda, enfrentar a las fuerzas armadas nicaragüenses que estaban ingresando al territorio costarricense, es decir, iniciar un conflicto militar con Nicaragua. Para los comunistas, esta era sin duda una situación complicada para el gobierno de Echandi e hicieron pública su posición asegurando:

121 La Nación, «La violación...», 14 de noviembre de 1959, 6.

122 República de Costa Rica, Colección de Leyes y Decretos, II Semestre, 1959, 511-512.

123 La Nación, «Poblados fronterizos...», 1 de febrero de 1960, 10.

124 La Nación, «Sentido humanístico...», 11 de febrero de 1960, 19; Alfonso González señala que Enrique Lacayo Farfán fue el principal jefe político y organizador de la invasión de junio-julio de 1959, ver: González, «Mujeres y hombres de la posguerra...», 4. 


\begin{abstract}
Nosotros simpatizamos, abiertamente, con todo movimiento que tienda a derrocar la dictadura que oprime al pueblo nicaragüense, pero, seguimos pensando, que Pastora escogió una táctica equivocada. Está bien que utilizara la libertad de que goza en nuestro país, y la simpatía que existe en todas las esferas sociales hacia la causa del pueblo nicaragüense, para organizar su lucha. Pero está mal que estableciera su campo de operaciones en territorio costarricense porque, al hacerlo, tenía que terminar obligando al Gobierno de Costa Rica a intervenir en el conflicto. ${ }^{125}$
\end{abstract}

Incluso, la teoría de los comunistas era que los liberacionistas que apoyaban a los nicaragüenses querían provocar un incidente internacional entre ambos gobiernos, que diera lugar a la intervención de la OEA. Además, señalaban que era ampliamente conocida la posición de Figueres propugnando la intervención del organismo internacional, tanto para el caso de República Dominicana como para Nicaragua. Por lo anterior, se concluía: «Estamos en presencia de una táctica trazada por quienes no quieren una verdadera revolución en Nicaragua, por quienes propugnan como salida a la dictadura actual unas elecciones presididas por una comisión de la OEA...»». ${ }^{126}$ Finalmente, el 22 de febrero se publicó un amplio reportaje sobre la rendición de Pastora y el anuncio de su salida de Costa Rica, junto a su hermano y a un grupo de 25 hombres, los cuales serían trasladados a El Salvador. Se detallaba que el padre de Pastora había llegado de El Salvador, invitado por Echandi, con el propósito de que se trasladara al campamento de su hijo y lo convenciera de desistir en sus planes.

En declaraciones del padre, se decía que le había expresado que «un movimiento revolucionario que no crece, perece». Por su parte, Pastora señaló que antes de abandonar Costa Rica quería dejar constancia «de mi agradecimiento con las autoridades y fuerzas de la Guardia Civil, así como el señor Presidente de la República. Hemos recibido un trato respetuoso y digno [...] Espero que se acaben las molestias y preocupaciones que hemos causado a este pueblo hospitalario que tanto queremos...»». ${ }^{127}$ De esta forma, llegó a su fin el conflicto generado producto de las acciones militares que estaban desarrollando opositores al gobierno de Somoza, desde el territorio costarricense.

Una solución negociada y sin víctimas, esta vez con los nicaragüenses. Desde un Editorial de La Nación se caracteriza como un acto que «es en realidad lo que tradicionalmente se ha conocido como «una solución a la tica». Sin humillaciones para nadie, sin poses ni marchas de vencedores [...] sin que se hubiera derramado una sola gota de sangre...»». ${ }^{128} \mathrm{Al}$ día siguiente, Echandi dio un discurso en el Colegio Vocacional Agropecuario en Santa Clara, San Carlos, donde retomó el mismo argumento «Hemos podido terminar con las actividades de

125 Adelante, «Definimos nuestro...», 13 de diciembre de 1959, 1 y 6.

126 Adelante, «Ayudan a la revolución...», 16 de agosto de 1959, 6; Adelante, «Solamente un cambio...», 19 de diciembre de $1959,3$.

127 La Nación, «Nada tenemos», 22 de febrero de 1960, 40.

128 La Nación, «Una solución a la tica», 22 de febrero de 1960, 6. 
ese grupo, que encabezaba Indalecio Pastora, y lo hemos logrado sin sangre, sin violencia, sin una sola víctima [...] ese problema ha sido resuelto «a la tica». ${ }^{129}$

Tal como había ocurrido con motivo del incidente de Punta Llorona, se recurre al argumento de que Costa Rica tiene una tradición de pacifismo en la resolución de conflictos, discurso vinculado con la necesidad de olvidar la violencia política que antecedió al gobierno de conciliación nacional dirigido por Echandi. De esta forma, la intensificación de las actividades de los exiliados y opositores a la dictadura somocista en Costa Rica, propiciaron el surgimiento de un discurso nacionalista que identificó a los nicaragüenses como amenazas a la estabilidad del país y a su vez, cohesionó a los distintos sectores políticos costarricenses bajo la premisa de defenderse de las amenazas externas.

\section{La declaración de amnistía de 1962}

Las elecciones presidenciales se realizaron el 4 de febrero de 1962, los principales candidatos fueron Calderón y Orlich, obteniendo la victoria este último, con lo cual el PLN volvía a dirigir el Poder Ejecutivo. Las palabras de Echandi sobre los resultados electorales fueron «le he dado al país la oportunidad de decir, sin presiones ni forzamientos de ninguna índole, sino con pleno disfrute de libertades y seguridades, su opinión política, a través de las urnas electorales, exclusivamente». ${ }^{130}$ De esta forma, la vía electoral se consolidaba como la única forma de alcanzar el poder en Costa Rica y los sectores antes enfrentados en la Guerra Civil de 1948 reafirmaban su renuncia a la vía armada. Precisamente, Calderón declaró al saber los resultados electorales:

\footnotetext{
Ofrecimos respetar el fallo del Tribunal Supremo de Elecciones y cumpliremos fielmente la promesa [...] Durante catorce años se nos calumnió y se nos maltrató [...] Recogimos la bandera de la conciliación nacional y con ella fuimos a la lucha política [...] Permaneceré en el país con los derechos de todo costarricense, amparado a las normas jurídicas vigentes y no como concesión gratuita de nadie. ${ }^{131}$
}

Por su parte, Orlich se apropió del discurso de unidad nacional que había caracterizado al gobierno de Echandi. Incluso, pidió a los liberacionistas «un pequeño sacrificio más», que desistieran de hacer celebraciones de carácter público. No obstante, se integró una comisión especial que se encargaría de los preparativos para el traspaso de poderes, tomándose la decisión de realizar festejos entre el seis y el nuevo de mayo. ${ }^{132}$ No es de extrañar que la victoria de Orlich fuera vista con preocupación por un sector de los vencidos de la Guerra Civil. Posiblemente, el recuerdo de la persecución política motivó a diputados

129 La Nación, «Tenemos derecho a vivir en paz...», 23 de febrero de 1960, 3.

130 La Nación, «El país pagó con creces...», 5 de febrero de 1962, 1.

131 La Nación, «Seguiré al frente...», 7 de febrero de 1962, 16.

132 La Nación, «Haremos un gobierno de Unidad Nacional», 5 de febrero de 1962, 1. 
calderonistas, entre ellos, Virgilio Calvo Sánchez, a presentar un proyecto de ley el 4 de mayo de 1962, cuyo objetivo era otorgar un indulto general a todas aquellas personas que sufrieron sentencias condenatorias dictadas por el TSI. Ello lo justificaba como una necesidad:

[...] restablecer en el país la más absoluta paz interna restañando las heridas que pudieren quedar abiertas con motivo de los hechos ocurridos en 1948. Tal sentimiento de liquidar definitivamente los odios encendidos en aquellos años lo vive ya el pueblo costarricense. El país requiere hoy el esfuerzo de sus mejores ciudadanos para la solución de los problemas económicos y sociales que lo agobian... ${ }^{133}$

El proyecto se discutió en la Asamblea Legislativa y se aprobó el 30 de mayo de 1962, es decir, cuando iniciaba la presidencia de Orlich. En esta ocasión, en lugar de utilizarse la palabra amnistía como había sucedido en 1955, se habló de indulto general para quienes habían sido condenados por delitos políticos o conexos por el TSI o cualquier otro tribunal de la República. ${ }^{134} \mathrm{Tal}$ vez, llamarle indulto era, de cierta forma, darle al proyecto, además de un valor legal, un significado moral. En palabras de Alberto Cañas, quien había sido electo diputado por el PLN: «No se trata de borrar el paso de unos hombres. Sino lo que de consecuencia trágica tenía ese paso. No hay nada deshonroso en un perdón. Las condenas están ya bastante purgadas. No hay nada deshonroso en tratar de terminar con 20 años de canibalismo político». ${ }^{135}$

\section{Conclusiones}

Desde la campaña electoral, Mario Echandi se presentó como la persona que lograría la conciliación nacional necesaria una década después de la Guerra Civil de 1948. Sin duda, su victoria en las elecciones presidenciales de 1958 demostró apoyo a su discurso de unidad de la familia costarricense. Como Díaz señala «la mayoría de los costarricenses estaba cansada de la persecución y la violencia y por eso abogaba por un fin de los conflictos internos que, en parte, fue ratificado por la elección de Echandi». ${ }^{136}$ Quizá la mayor incertidumbre al inicio de su período era si su discurso recibiría el sustento de la oposición en la Asamblea Legislativa y particularmente, de los vencedores y excombatientes.

El período de Echandi se caracterizó por una serie de transformaciones en las relaciones políticas de quienes, anteriormente, se habían enfrentado en el campo de batalla. En primer lugar, los calderonistas habían recuperado el derecho a participar en la política nacional por medio de las elecciones, logrando que los hermanos Calderón fueran electos diputados. Esta reincorporación es

133 La República, «Indulto general para los condenados...», 5 de mayo de 1962, p. 7.

134 República de Costa Rica, Colección de Leyes y Decretos, I Semestre 1962, 419.

135 La República, «Asamblea decretó...», 29 de mayo de 1962, 1 y 4.

136 Díaz Arias, Crisis social y memorias en lucha..., 320. 
interpretada por Alfonso González como el proceso en que «los calderonistas fueron rehabilitados como parte de la comunidad nacional». ${ }^{137}$ Lo anterior dio lugar al regreso del Doctor a Costa Rica, quien fue recibido el 8 de junio de 1958 por una gran manifestación popular, a pesar de la fuerte oposición de los excombatientes por considerarlo una provocación y una amenaza a la estabilidad del país. Así, se llevó a cabo el Desfile de la Concordia Nacional.

En 1958 se marcó el inicio de una nueva etapa en la política nacional. Llegó a la presidencia un político que no era identificado directamente con los bandos enfrentados en la Guerra Civil de 1948, quien además había sido víctima de la violencia política de la posguerra. Es claro, además, que el fracaso en las dos invasiones de 1948 y 1955 y la muerte de Anastasio Somoza García, quien había respaldado las aventuras militares, habían hecho a Calderón reconsiderar sus estrategias políticas, renunciando a la vía armada. Al formar parte de la Asamblea Legislativa, los hermanos Calderón estaban aceptando como único mecanismo de acceso al poder, la vía electoral. No obstante, los comunistas permanecieron excluidos de la participación electoral.

Los rituales políticos de inclusión, clasificados en esta investigación como «la recuperación de derechos y espacios» y «las medidas de compensación», se orientaron al reconocimiento de la violación de los derechos de los vencidos como resultado de la persecución política que se desencadenó en la posguerra. En el caso de los comunistas, reafirmaron el acceso a medios de comunicación como la prensa y la radio, el derecho a manifestarse en las calles sin pasar por una serie de controles estatales y la inviolabilidad de la correspondencia. Así como la aprobación de la revisión de las sentencias emitidas por el Tribunal de Probidad, a solicitud de los afectados. Es probable que esta legislación incentivara el regreso de exiliados, sin embargo, aún es necesario realizar una investigación al respecto.

También, durante el gobierno de Echandi se dirigió una política de desmantelamiento de los arsenales, lográndose un intercambio con una compañía estadounidense que recibió las armas a cambio de tractores y maquinaria agrícola. Este ritual político fortaleció la representación de Costa Rica como país con una tradición de pacifismo y neutralidad. Justo, en un contexto regional que empezaba a complicarse, en primer lugar, por las fuerzas opositoras al régimen nicaragüense que estaban operando en la zona norte de Costa Rica mediante las provocaciones a la Guardia Nacional, especialmente entre 1959-1960 y, en segundo lugar, por el triunfo de la Revolución Cubana.

Ahora, si bien la conciliación nacional empezó a gestarse desde antes del gobierno de Echandi, es innegable que tuvo la voluntad política de promover políticas en esa línea, a diferencia de los gobiernos de Figueres y de Ulate. En

137 González, Mujeres y hombres de la posguerra..., 6. 
este sentido, es fundamental señalar que la declaración de amnistía de 1955 no fue una concesión de Figueres, sino el resultado de la lucha de diversos sectores, particularmente, de las mujeres, quienes reclamaron su aprobación como una forma de sellar con la legalidad y el olvido, la violencia política. Además, las actividades realizadas por fuerzas armadas opositoras a la dictadura somocista en la zona norte del país contribuyeron al surgimiento de un discurso nacionalista que decantó en la cohesión para enfrentar las amenazas externas.

El proceso de conciliación nacional concluyó con la aprobación, el 30 de mayo de 1962, de un indulto general para todos los costarricenses sentenciados por delitos políticos o conexos. Esta política había sido impulsada por los calderonistas, posiblemente como escudo ante la llegada de Orlich a la presidencia. A nivel regional, el triunfo de la Revolución Cubana iniciaba una nueva etapa del anticomunismo, por ejemplo, el 29 de marzo de 1962 se autorizó el funcionamiento de la "Asociación Movimiento Costa Rica Libre», ${ }^{138}$ mientras que la llegada de John F. Kennedy a la presidencia de los Estados Unidos significó la puesta en marcha de un «anticomunismo ilustrado» impulsado mediante la Alianza para el Progreso. ${ }^{139}$ Probablemente, ante las nuevas dinámicas regionales producto del contexto de Guerra Fría, a los Estados Unidos les favorecía que Costa Rica fuera un país democrático, desarmado y aliado incondicional.

\section{Bibliografía}

Ameringer, Charles. Don Pepe: A Political Biography of José Figueres of Costa Costa Rica, México D.F.: University of New Mexico Press, 1978.

Asamblea Legislativa de la República de Costa Rica, «Expresidentes de Costa Rica. Mario Echandi Jiménez».

http://www.asamblea.go.cr/ca/Expresindentes $\% 20 \mathrm{de} \% 20 \mathrm{Costa} \% 20 \mathrm{Rica} /$ Forms/DispForm.aspx?ID=30.

Bowman, Kirk. «¿Fue el compromiso y consenso de las élites lo que llevó a la consolidación democrática en Costa Rica? Evidencia de la década de 1950». Revista de Historia, n. 41 (enero-junio, 2000): 91-127, https://www.revistas.una.ac.cr/index.php/historia/article/view/1868/1772.

Díaz Arias, David. «A los pies del águila: la visita de John F. Kennedy a Costa Rica en 1963». En: Iván Molina y David Díaz (eds.), El verdadero anticomunismo. Política, género y Guerra Fría en Costa Rica (1948-1973). San José, Costa Rica: EUNED, 2017.

Díaz Arias, David. Crisis social y memorias en lucha: guerra civil en Costa Rica, 1940-1948. San José, Costa Rica: EUCR, 2015.

138 República de Costa Rica, Colección de Leyes y Decretos, I Semestre 1962.

139 David Díaz Arias, «A los pies del águila: la visita de John F. Kennedy a Costa Rica en 1963», en: Iván Molina y David Díaz (eds.) El verdadero anticomunismo. Política, género y Guerra Fría en Costa Rica (1948-1973) (San José, Costa Rica: EUNED, 2017), 181-214. 
Echandi Jiménez, Mario. «Discurso del traspaso de poderes», 8 de mayo de 1958. https://ocs. google.com/viewer? $\mathrm{a}=\mathrm{v} \&$ pid=sites\&srcid=ZGVmYXVsdGRvbWFpbnxtZW5zYWplcHJlc21kZW5jaWFsY3J8Z3g6NGExZmMwZGQzY2Q3MTljOQ.

Echandi Jiménez, Mario. «Discurso presentado ante la Asamblea Legislativa», 1 de mayo de 1959.

https://docs.google.com/viewer?a=v\&pid=sites\&srcid=ZGVmYXVsdGRvbWFpbnxtZW5zYWplcHJlc21kZW5jaWFs Y3J8Z3g6ZDFmNTViMzZmNGJhNDdl.

Figueres Ferrer, José. «Traspaso de poderes», Mensajes Presidenciales 19401058, T. VII, Carlos Meléndez (ed.). San José, Costa Rica: Imprenta Nacional, 1990.

Gamboa, Manuel. «Los discursos políticos durante las campañas electorales entre 1953 y 1970 en Costa Rica: la memoria de la Guerra Civil de 1948». Tesis de licenciatura en Historia, Universidad de Costa Rica, 2012). http://www.kerwa.ucr.ac.cr/bitstream/handle/10669/853/Tesis\%20\%20 de $\% 20$ Historia $\% 20$-Manuel $\% 20$ Gamboa.pdf? sequence=1\&isAllowed $=\mathrm{y}$.

González, Alfonso. Mujeres y hombres de la posguerra 1950-1960. Costa Rica: San José: EUCR, 2005.

Quirós, Claudia. Los tribunales de Probidad y de sanciones inmediatas. Centro Regional de Occidente, Coordinación de Investigación.

Rodríguez, Corina. "Carta abierta al diputado...», La Nación, 31 de mayo de $1958,3$.

Schifter, Jacobo. La fase oculta de la guerra civil en Costa Rica. Costa Rica: Editorial Universidad Centroamérica, 1986.

Solís Avendaño, Manuel. La institucionalidad ajena. Los años cuarenta y el fin de siglo. San José: EUCR, 2006.

Ugalde Quesada, Alexia. «"Caínes despiadados... Caínes invasores”. La invasión del 10 de diciembre de 1948 a Costa Rica en perspectiva nacional y transnacional», Anuario de Estudios Centroamericanos, n. ${ }^{\circ} 46$ (2020): 1-33. https://doi.org/10.15517/aeca.v46i0.42206.

Ugalde Quesada, Alexia. «Nicaragua y la invasión de 1955 en los discursos de la prensa costarricense». Anuario de Estudios Centroamericanos, n. ${ }^{\circ} 42$ (2016): 295-325. https://doi.org/10.15517/aeca.v42i1.26951.

Ugalde Quesada, Alexia. «"Purificarse en las aguas del Jordán”. La ruta política y social de la amnistía de 1955 en Costa Rica y la participación de las mujeres», Diálogos Revista Electrónica de Historia, vol. 21, n. ${ }^{\circ} 1$ (enero-junio, 2020): 37-66. https://doi.org/10.15517/dre.v21i1.38244.

\section{Fuentes primarias}


Archivo Nacional de Costa Rica (ANCR), Material Divulgativo de Pequeño Formato (MADIPEF), 1201.

ANCR, Ministerio de Economía y Comercio (MEIC), 2575.

ANCR, Ministerio de Economía y Comercio (MEIC), 2166.

ANCR, Ministerio de Gobernación (MG), 36406.

ANCR, Ministerio de Gobernación (MG), 40315.

ANCR, Ministerio de Gobernación (MG), 41484.

ANCR, Ministerio de Gobernación (MG), 41795.

ANCR, Ministerio de Seguridad Pública (MSP), Dirección General de Detectives (DGDET), 889.

República de Costa Rica, Colección de Leyes y Decretos, II Semestre, 1958.

República de Costa Rica, Colección de Leyes y Decretos, II Semestre, 1959.

República de Costa Rica, Colección de Leyes y Decretos, I Semestre, 1962.

República de Costa Rica, Colección de Leyes y Decretos, II Semestre 1962.

\section{Periódicos}

Adelante, «Al desarmarse Costa Rica...», 6 de diciembre de 1959, 1.

Adelante, «Ayudan a la revolución...», 16 de agosto de 1959, 6 .

Adelante, «Definimos nuestro...», 13 de diciembre de 1959, 1 y 6.

Adelante, «El Congreso anti-comunista...», 1 de febrero de 1959, 3.

Adelante, «El Congreso dio a luz...», 1 de febrero de 1959, 1.

Adelante, «Las mujeres de Puntarenas...», 6 de diciembre de 1959, 5.

Adelante, «Quien dirigió el atentado...», 20 de julio de 1958, 2.

Adelante, «Restablecida la libertad...», 6 de diciembre de 1959, 1.

Adelante, «Sensacional discurso...», 4 de mayo de 1958, 4.

Adelante, «Si los excombatientes promueven...», 1 de junio de 1958, 1 y 6.

Adelante, «Solamente un cambio...», 19 de diciembre de 1959, 3.

Adelante, «V.P. enfoca situación política...», 22 de febrero de 1959, 4.

La Gaceta, «Proyecto revisión de sentencias», 17 de julio de 1958, 1.

La Hora, «Acción judicial contra reservistas...», 14 de agosto de 1958, 8.

La Hora, «Ametrallada...», 14 de julio de 1958, 1 y 5.

La Hora, "Armamento fue entregado...», 23 de agosto de 1958, 1 y 8.

La Hora, «Calderón Guardia llegó a Nicaragua», 26 de mayo de 1958, 1.

La Hora, «Concentrada la fuerza pública», 7 de junio de 1958, 1.

La Hora, «Conferencia Echandi Jiménez-Calderón Guardia», 29 de abril de 1958,1 y 8.

La Hora, «Conmemoración de la lucha armada del 48», 7 de abril de 1958, 8 .

La Hora, «Exigimos...», 18 de setiembre de 1958, 3.

La Hora, «Intervención...», 21 de julio de 1958, 1.

La Hora, «Ninguna resolución del gobierno...», 28 de mayo de 1958, 1.

La Hora, «Requisa de armas...», 3 de junio de 1958, 1. 
La Hora, «Totalmente falso...», 18 de setiembre de 1958, 3.

La Nación, «Agradezcamos al Señor esta bendición...», 9 de mayo de 1958, 1 y 7.

La Nación, «A las 10...», 30 de mayo de 1958, 8.

La Nación, «A la sabana», 27 de mayo de 1958, 14.

La Nación, «Ametralladoras y cañones...», 2 de diciembre de 1959, 7.

La Nación, «Antes que todo, buscar fórmulas...», 9 de agosto de 1958, 31.

La Nación, «Apedreadas...», 4 de junio de 1959, 4.

La Nación, «Apelación a la prudencia», 7 de junio de 1958, 6 .

La Nación, «Apoyo moral a la revolución en Nicaragua», 3 de junio de 1959, 4-5.

La Nación, «A punto de ser linchado el Dip. Echandi...», 2 de febrero de 1955, 5. La Nación, «Arreglada organización del recibimiento...», 1 de junio de 1958, 4. La Nación, «Bandas militares», 25 de abril de 1959, 18.

La Nación, «Bello desfile patriótico», 17 de setiembre de 1958, 40.

La Nación, «Brilla de nuevo en la Casa Presidencial...», 11 de mayo de 1948, 1.

La Nación, «Cambio de armas por tractores», 28 de diciembre de 1959, 8.

La Nación, "Comité de radio...», 11 de noviembre de 1958, 16.

La Nación, «Condeno definitivamente el atentado», 15 de julio de 1958, 1-2.

La Nación, «Consejo de Gobierno...», 9 de agosto de 1959, 8.

La Nación, «Concentración de exiliados...», 28 de julio de 1959, 29.

La Nación, «Corregir injusticias...», 26 de agosto de 1958, 18.

La Nación, «Desaparece otro cuartel», 19 de febrero de 1960, 1 y 29.

La Nación, «Descubierta una red terrorista...», 1 de abril de 1951, 30.

La Nación, «Devolver folletos...», 3 de diciembre de 1959, 27.

La Nación, «Devuelven Reservistas...», 6 de julio de 1958, 58.

La Nación, «Dios quiera que en nuestra querida Patria...», 8 de mayo de 1958, 4.

La Nación, «El atentado contra el Dr. Calderón», 15 de julio de 1958, 6.

La Nación, «El gobierno no persigue...», 20 de junio de 1959, 24-25.

La Nación, «El país pagó con creces...», 5 de febrero de 1962, 1.

La Nación, «En defensa de nuestra paz», 9 de junio de 1959, 12.

La Nación, «En medio de un escándalo inauguró sus sesiones...», 3 de mayo de 1958, 12.

La Nación, «Explica el Partido Republicano», 20 de noviembre de 1958, 24.

La Nación, «Frontera Norte», 13 de noviembre de 1959, 15.

La Nación, «Fueron tantos... que es imposible decir cuántos...!», 12 de junio de 1958, 24-25.

La Nación, «Gastando los millones en ejércitos», 1 de setiembre de 1957, 12.

La Nación, «Hagamos patria», 26 de agosto de 1958, 4.

La Nación, «Haremos un gobierno de Unidad Nacional», 5 de febrero de 1962, 1. 
La Nación, «Impactos de calibre 45», 15 de julio de 1958, 1 y 15.

La Nación, «Informa la comisión...», 18 de noviembre de 1959, 11.

La Nación, «Informe de las autoridades que practicaron...», 21 de junio de 1959, 62.

La Nación, «La OEA desconoce...», 20 de junio de 1959, 4.

La Nación, «La violación...», 14 de noviembre de 1959, 6.

La Nación, «Ley de cambio de armas...», 13 de noviembre de 1959, 3.

La Nación, «Líder comunista Carlos Luis Fallas...», 8 de enero de 1960, 8.

La Nación, «Magnífico espectáculo», 9 de mayo de 1958, 25.

La Nación, «Muestra pública de simpatía...», 18 de junio de 1959, 8.

La Nación, «Nada tenemos», 22 de febrero de 1960, 40.

La Nación, «No he venido a hacer política», 10 de junio de 1958, 18.

La Nación, «Nota de protesta...», 16 de noviembre de 1959, s.p.

La Nación, «No viene a hacer política ni a cobrar agravios», 6 de mayo de 1958, 50.

La Nación, «ORDEN Y PAZ», 27 de mayo de 1958, 18.

La Nación, «Otro debate político», 2 de setiembre de 1958, 1 y 9.

La Nación, «Para garantizar neutralidad...», 1 de agosto de 1959, 7.

La Nación, «Para lograr la paz y la armonía...», 27 de agosto de 1958, 9.

La Nación, «Partido Republicano», 25 de mayo de 1958, 16.

La Nación, «Paz respetada por todos...», 20 de mayo de 1958, 38.

La Nación, «Poblados fronterizos...», 1 de febrero de 1960, 10.

La Nación, «Preferible que se excedan...», 21 de setiembre de 1958, 11.

La Nación, «Primero Costa Rica...», 26 de junio de 1959, 4.

La Nación, «Propaganda roja», 17 de octubre de 1958, 26.

La Nación, «Ratifica ante los Tribunales Comunes...», 18 de julio de 1958, 5.

La Nación, «Renacimiento», 10 de junio de 1958, 6.

La Nación, «Retrato del ex-Presidente Picado...», 7 de junio de 1958, 8.

La Nación, «Reveladas intimidades de la entrevista...», 14 de agosto de 1958, 14.

La Nación, «Revisión de las sentencias», 15 de julio de 1958, 1 y 12.

La Nación, «Revisión de sentencias...», 13 de noviembre de 1959, 12 y 19.

La Nación, «Se encendió el debate político...», 3 de setiembre de 1958, 38.

La Nación, «Seguiré al frente...», 7 de febrero de 1962, 16.

La Nación, «Sentido humanístico...», 11 de febrero de 1960, 19.

La Nación, «Sin ser amigos ni enemigos...», 18 de julio de 1958, 2.

La Nación, «Si todos miramos el interés nacional...», 25 de mayo de 1958, 70.

La Nación, «Suspendidos dos diputados en sus funciones», 2 de febrero de 1955, 14.

La Nación, «Terminó la aventura...», 24 de junio de 1959, 4.

La Nación, «Tenemos derecho a vivir en paz...», 23 de febrero de 1960, 3.

La Nación, «Términos en que el gobierno...», 15 de noviembre de 1959, 17. 
La Nación, «Una solución a la tica», 22 de febrero de 1960, 6.

La Nación, «Un enorme arsenal...», 20 de junio de 1959, 1, 22 y 25.

La Nación, «Yo sé que la paz asfixia...», 4 de marzo de 1959, 1.

La Nación, «iUn momento, señor Echandi!», 9 de julio de 1958, 1.

La República, «A los costarricenses», 1 de mayo de 1958, 8.

La República, «Asamblea decretó indulto general...», 29 de mayo de 1962, 1 y 4.

La República, «Asociación de excombatientes... », 24 de mayo de 1958, 1 y 20.

La República, «Con los excombatientes», 28 de mayo de 1958, 6.

La República, «Echandi hablará a las juntas progresistas», 14 de setiembre de 1958, 17.

La República, «El Misterio de Educación Pública», 14 de setiembre de 1958, 20.

La República, «Es una farsa la conciliación nacional», 29 de mayo de 1958, 12-13.

La República, «Indulto general para los condenados...», 5 de mayo de 1962, p. 7.

La República, «Pedido el permiso para el recibimiento...», 22 de mayo de 1958, 10.

La República, «Pronunciamiento...», 20 de junio de 1954, 6.

Nuestra Voz, «Carta a la primera dama...», junio de 1959, 1-2.

Nuestra Voz, «Comisión de Mujeres...», julio de 1959, 3. 